\title{
Support Schemes for Renewable Electricity in the European Union: Producer Strategies and Competition
}

\author{
Luisa Dressler \\ Université libre de Bruxelles, Solvay Brussels School of Economics and Management and \\ ECARES, Avenue F.D. Roosevelt 50, CP114, B-1050 Brussels, Belgium.
}

\begin{abstract}
Current discussion about how to reform European support schemes for renewable electricity neglects certain risks of market power in wholesale electricity markets. In a stylized Cournot model of interacting spot and forward electricity markets, I analyze how different price-based support schemes affect producer strategies and, ultimately, competition in the wholesale market. I compare the strategic behavior of renewable and conventional producers in terms of electricity production and forward market sales in the presence of two different price-based support schemes: feed-in tariffs and feed-in premiums. I show that the feed-in premium, which is the European Commission's current scheme of choice, may enhance market power and favor conventional electricity production. It may also reduce the likelihood of achieving the political objective to increase production from renewable energy sources.
\end{abstract}

Keywords: Renewable electricity, Feed-in tariff, Feed-in premium, Oligopoly, Forward market

JEL: L13, L98, Q42, Q48

\section{Introduction}

European support schemes that promote the use of renewable sources of energy in electricity production are attracting fierce criticism. They are blamed for distorting the internal European electricity market and for driving up consumer prices (European Commission, 2012a). Support schemes for renewable electricity are in place to reach the policy objective of increasing the production of electricity from renewable sources of energy. ${ }^{1}$ However, the European Commission has

\footnotetext{
Email address: luisa.dressler@ulb.ac.be (Luisa Dressler)

${ }^{1}$ The goal to integrate a $20 \%$ share of renewable energy in the European Union's final energy consumption for 2020 is legally formalized in the Renewable Energy Directive (2009/28/EC)
} 
asked for existing support schemes to be reviewed, with the aim of bringing renewable electricity closer to the market to enhance competition and market efficiency (European Commission, 2012a, 2014a).

Although competition and market efficiency are eventually driven by producer behavior, current discussions about how to design efficient support schemes for renewable electricity are not informed by comprehensive microeconomic analysis of how different price-based support schemes influence producer behavior. It has been shown, that wholesale electricity markets are prone to market power and that market competition is influenced by producer strategies (Wolfram, 1999; Wolak and Patrick, 2001; Borenstein et al., 2002; Joskow and Kahn, 2002; Mansur, 2007; Weigt and von Hirschhausen, 2008). However, the microeconomic literature has disregarded the strategic behavior of electricity producers - and their impact on wholesale market competition - in the presence of price-based support schemes for renewable electricity. ${ }^{2}$

Whereas there is a debate about possible impacts of price-based support schemes on incentives for investment in generation capacity, this debate does not look at how these support schemes affect producer strategies in wholesale electricity markets conditional on capacity investment being installed. Answering this question is important. Support schemes do not only come as a reward for renewable investment, some of them transform electricity producers into strategic participants in wholesale markets, with implications for market power and competition.

This article takes a game-theoretic approach and analyzes the impact of pricebased support schemes for renewable electricity on the strategic behavior of conventional and renewable electricity producers and, ultimately, on wholesale market competition. It does not study the effect of support schemes on consumer prices or capacity investment.

Because the time horizon of electricity wholesale markets differs, my article aims at understanding the production and trading behavior of electricity producers active on the intraday (i.e. spot) and the day-ahead (i.e. forward ${ }^{3}$ ) electricity market, building on work of Allaz and Vila (1993). In a symmetric Cournot duopoly

and is complemented by mandatory national targets for each member state. In 2014, the European heads of state and government have agreed on a EU-wide binding target of $27 \%$ for 2030 (European Council, 2014).

${ }^{2}$ This article looks at price-based instruments in particular. There is a literature analyzing strategic effects under quantity-based policies supporting the production of electricity from renewable sources of energy, such as green certificates: e.g. Amundsen and Mortensen (2001), Jensen and Skytte (2002), Fischer (2010), Schmalensee (2011), Amundsen and Bergman (2012) and Tanaka and Chen (2013).

${ }^{3}$ Electricity that has been sold on the day-ahead market is not delivered before the day after, which characterizes the day-ahead market as a forward market. A similar definition has been adopted in Borenstein et al. (2008) and Holmberg (2011). 
that sells a homogeneous commodity, Allaz and Vila demonstrate the emergence of a forward market even if participants are risk neutral and there is, therefore, no risk-hedging motive. They find that forward trading strengthens competition and efficiency in the market. Each producer has a unilateral incentive to use the forward market as a commitment device for higher production. ${ }^{4}$ Ultimately both producers sell on the forward market and are worse off, because total production increases pushing equilibrium prices down.

I apply the Allaz and Vila (1993) framework to the electricity market and extend the model by introducing an asymmetric renewable producer and by analyzing the production and forward trading behavior of conventional and renewable producers under different price-based support schemes for renewable electricity. Renewable production differs from conventional one in marginal cost and the available capacity. I consider two price-based support schemes for renewable electricity: feed-in tariffs and feed-in premiums.

In a feed-in tariff system, during a guaranteed amount of time, the renewable energy producer receives a statutory fixed amount per kWh of electricity produced. As a result, the producer is not exposed to market signals and does not actively participate in the market. Feed-in tariffs have been used in most of the European member states and are heavily criticized to generate market inefficiencies and excessive cost burden for consumers. ${ }^{5}$

Under a premium scheme, renewable energy producers sell their electricity actively in the market and are granted a premium on top of the market price. Because it partially exposes renewable energy producers to market price risks, the premium scheme is said to help integrate renewable electricity into the market and to decrease market distortions (European Commission, 2012b). Therefore, and as opposed to feed-in tariffs, it meets the European Commission's requirements of state aid for electricity from renewable energy sources for the period after January 2016 that are set out in paragraph 124(a) of the Guidelines on State aid for environmental protection and energy 2014-2020 (European Commission, 2014b). At least two types of premium schemes are discussed: a floating premium, under which a variable subsidy complements the market price to guarantee a fixed remu-

\footnotetext{
${ }^{4}$ The possibility of selling on a forward market creates a trade-off for the producer: (1) Following a Stackelberg type of reasoning, locking in quantities by forward sales increases his production (profit tends to increase). (2) Producing more quantities, however, decreases equilibrium prices (profit tends to decrease). Allaz and Vila (1993) argue that the incentive to lock in quantities (and increase profits) dominates, because any ex-post price decrease applies to spot market sales only. Therefore, expanding production becomes profitable.

${ }^{5}$ To cover the difference between feed-in tariff and market price, a surcharge is generally passed on to the final electricity consumer. The surcharge typically increases as more renewable electricity is produced, driving down market prices. Furthermore, receiving a fixed price creates no incentives for renewable energy producers to efficiently dispatch and reduce production costs.
} 
neration, ${ }^{6}$ and a fixed premium, under which a fixed subsidy is paid at any market price.

Each scheme will affect the strategic behavior of producers in wholesale electricity markets quite differently. Understanding the ultimate impact on competition, which I measure in terms of wholesale prices, is not straightforward. Two main competitive effects have been underlined in previous studies:

First, the economic literature regularly uses the seminal paper of Allaz and Vila (1993) to study electricity markets (e.g. Powell, 1993; Kamat and Oren, 2004; Bushnell, 2007) and widely acknowledges that forward markets have beneficial effects on competition. ${ }^{7}$ The pro-competitive impact of forward electricity markets was confirmed experimentally by Le Coq and Orzen (2006), Brandts et al. (2008), van Koten and Ortmann (2013) and Ferreira et al. (2016). Further evidence has been provided by the empirical literature (e.g. Wolak, 2000; Fabra and Toro, 2005; Bushnell et al., 2008). Only a few studies model renewable electricity in a set-up with forward markets (e.g. Twomey and Neuhoff, 2010; Liski and Montero, 2014; Knaut and Obermüller, 2016), but do not analyze how different support schemes perform in such a framework. My article contributes towards explaining this issue.

A second aspect of competition is important for my analysis. Due to its zero marginal cost, renewable electricity will be at the bottom of the merit order curve on the electricity exchange, ${ }^{8}$ which pushes wholesale electricity prices down. This phenomenon is known as the merit order effect (e.g. Sensfußet al., 2008; Sáenz de Miera et al., 2008). Models that study this short-term competitive effect of renewable electricity generally disregard the strategic behavior in renewable and conventional electricity production or model strategies of the conventional producer in isolation. However, it is not clear how interacting producer strategies materialize and in what way they differ under different support schemes. To the best of my knowledge, no analytical microeconomic research has tried to answer this question. My model will be critical in this respect as it studies the interaction of renewable and conventional electricity production in the presence of different price-based support schemes for renewable electricity.

My analysis of electricity market competition under price-based support schemes for renewable electricity yields two main results.

First, the competitive effect of switching from a feed-in tariff to a premium

\footnotetext{
${ }^{6}$ Broadly speaking, the floating premium equals the feed-in tariff minus the market price.

${ }^{7}$ It has been shown that the pro-competitive effect of forward markets is reduced or reversed if main assumptions of the model are changed, e.g. if forward positions are not observable (Bagwell, 1995; Hughes and Kao, 1997), if producers compete à la Bertrand (Mahenc and Salanié, 2004) or if a dynamic framework is chosen (Ferreira, 2003; Liski and Montero, 2006).

${ }^{8}$ The merit order curve represents the supply curve at the electricity exchange and ranks the available generating technologies according to their short-run marginal costs.
} 
scheme depends on the design of the premium. As opposed to a fixed premium, a floating premium is equivalent to a feed-in tariff in terms of producer strategies and competition. Under both schemes, the floating premium and the feed-in tariff, renewable producers receive a fixed and positive remuneration. All renewable electricity will literally be dumped on the market whenever it is available in real time. Equilibrium prices adapt accordingly and are the same under both schemes.

Second, using a fixed premium instead of the feed-in tariff transforms renewable electricity producers into strategic market participants with two counteracting effects on competition. On the one hand, the renewable producer has an incentive to withhold production capacity in order to drive up prices (anti-competitive effect). On the other hand, he has an incentive to use the forward market to influence conventional electricity production as shown in Allaz and Vila (1993) (pro-competitive effect).

The net effect on wholesale market competition under a fixed premium depends on the amount of renewable energy that is available and the level of the premium. ${ }^{9}$ Market power is most likely to prevail when a lot of renewable electricity is available and when the premium is low. In such situations, conventional electricity producers gain relative to a feed-in tariff world, whereas renewable production is reduced. Because of the current political will to promote renewable energy production at lowest cost, such a situation is likely to arise more frequently in the future. Thus, shifting towards a fixed premium puts at risk market competition and compliance with the political target to increase electricity production from renewable energy sources.

These findings support the main conclusion of the article. Although the change in support schemes for renewable electricity from a feed-in tariff towards a premium was motivated by market integration and efficiency, it may actually increase market power and lead to inefficiencies in those parts of the market that are considered in my model. This result relates to the argumentation of Europe's leading energy economists. In an open letter to the responsible European Commissioners (Fabra et al., 2014), they recently warned against a number of other potential negative impacts that are linked to the introduction of a feed-in premium.

The next section outlines my basic theoretical model. In Section 3 and 4, I determine equilibrium strategies and wholesale prices under a feed-in tariff and feed-in premium respectively. Section 5 analyses in detail the strategic effects that arise when a feed-in premium replaces a feed-in tariff. Section 6 discusses my results in a broader context and Section 7 closes with some final remarks.

\footnotetext{
${ }^{9}$ These strategic effects disappear when the level of the premium is very generous. If the remuneration is too high, all available renewable electricity will be dumped on the market and the price effect under both support schemes, the feed-in tariff or the fixed premium, is the same.
} 


\section{The model: set-up and notation}

My model extends the Allaz and Vila (1993) Cournot set-up by integrating a renewable electricity producer that is promoted by either a feed-in tariff or a premium scheme. Following the reasoning of Borenstein and Bushnell (1999), I use a Cournot and not a Bertrand model of oligopolistic competition, because market power in the electricity wholesale market may take the form of producers declaring generation capacity unavailable in the short run, for example for maintenance reason. ${ }^{10}$ This makes the Cournot framework of competition via quantities more suitable. Furthermore, in my model renewable electricity may face a production constraint which violates the Bertrand paradigm. ${ }^{11}$ Choosing a Cournot framework is likely to amplify any form of market power, because firms behave like monopolists facing residual demand. Using a static Cournot instead of a supply function equilibrium model has the advantage of providing unique solutions. The Cournot case can be seen as a static worst case scenario of supply function equilibria. As a consequence, my results will be only part of the truth but will point out exactly those areas in which policy makers need to be particularly careful.

In my set-up there is one conventional $(c)$ and one renewable electricity producer $(r)$. The latter generates electricity from a renewable source of energy (e.g. wind or sun). He differs from the conventional producer in two respects: first, his marginal cost is zero (i.e. wind blows and the sun shines without costs) and second, his production is variable and depends on the availability of the energy source (i.e. the amount of wind or sun). Both producers are risk neutral.

Contrary to other articles, I do not model the renewable electricity producer as a fringe producer but as a full market participant. Individual renewable electricity producers are among the three to seven largest electricity producers in terms of their installed capacity in Denmark, the Netherlands, Portugal and Spain already today. ${ }^{12}$ The trend towards large market shares of single renewable producers is likely to strengthen if the past strong growth in market shares of big individual renewable producers continues in the future. ${ }^{13}$ Therefore, it is more and more

\footnotetext{
${ }^{10}$ E.g. Wolak and Patrick (2001) have shown that producers in England and Wales obtained higher prices by withholding capacities.

${ }^{11}$ The Bertrand mechanism only works properly when firms are able to reduce prices below those of their competitors and to expand output so as to capture the whole market.

${ }^{12}$ For instance, in Denmark 2014 the third largest electricity producer in terms of installed capacity was a renewable producer with a market share of $7 \%$, which was only slightly below the $11 \%$ market share of the second largest producer. In Spain, the market share of the largest renewable producer was $3 \%$, compared to a $18 \%$ market share of the largest conventional producer. Source: Own calculation based on Platts UDI World Electric Power Platts Data Base.

${ }^{13}$ Between 2010 and 2014, the largest renewable electricity producer in Denmark gains two additional percent of the total market in terms of installed capacity (from $5 \%$ to $7 \%$, i.e. $+35 \%$ ).
} 
difficult to justify modeling renewable electricity producers as fringes.

This article describes electricity production in a deterministic framework, because it focuses on understanding the strategic behavior of electricity producers and wants to abstract from their attitude towards risk. To account for the variability of the renewable energy source, I analyze the model for different realizations of this energy source by introducing a constraint on renewable production that may take different levels. This comes down to assuming that the available amount of renewable energy is known by the time the day-ahead market opens but that renewable energy levels vary over time. In that sense, variability can be defined in terms of diurnal cycles of solar radiation that are generally predictable the dayahead. With respect to wind energy this assumption is slightly stronger. However, the day-ahead forecast error for wind is steadily decreasing because of technological developments and improvements in power forecast models and weather forecasts. Section 6 discusses the sensitivity of my results in the presence of uncertainty about renewable electricity production.

The following variables are used in the model.

Production: $q_{c}$ and $q_{r}$ represent the electricity production of producer $c$ and $r$ respectively. Both are non-negative. Otherwise, conventional production is unconstrained. Renewable production is constrained to $k>0$. $k$ represents the amount of renewable energy that is available and may take any level.

Costs: Because this article does not focus on investment incentives, neither producer faces fixed costs. The conventional producer has linear production costs with marginal cost $c>0$. The renewable producer's marginal cost is zero if energy is available for production and infinite otherwise.

Demand: Market demand is represented by the inverse demand function $p=$ $a-Q$, where $a$ is the maximum willingness to pay and $Q=q_{c}+q_{r}{ }^{14}$ It is assumed that $a-k>c$ to exclude trivial results, that is to ensure that every player has an interest to produce. ${ }^{15}$

Timing: There are two sequential markets for electricity: a forward and a spot electricity market. Electricity trading takes place in two stages:

In the United Kingdom the largest renewable producer gains one additional percent of the total market (i.e. $+92 \%$ ) Source: Own calculation based on Platts UDI World Electric Power Platts Data Base.

${ }^{14}$ Although, the support for electricity from renewable sources might ultimately be financed by a consumption tax that could depress consumer demand, I model demand as independent of the support scheme because of the low price-elasticity of demand in the short run.

${ }^{15}$ When $a-k>c$, prices at minimum residual demand for conventional electricity (market demand net of maximum available renewable electricity) exceeds the marginal cost of the conventional producer. 
- $\mathrm{t}=\mathbf{1}-$ Forward market:

The producers may sign binding and observable forward contracts $\left(f_{c}\right.$ and $f_{r}$ ) that need to be delivered in $\mathrm{t}=2$. Competitive speculators represent the demand for forward positions.

- $\mathbf{t}=\mathbf{2}$ - Spot market and Electricity Production:

The producers generate electricity $\left(q_{c}\right.$ and $\left.q_{r}\right)$ and compete in the spot market taking into consideration the forward positions contracted in $\mathrm{t}=1$.

Prices: The spot market price clears the spot market. Whatever forward sales, spot market inverse demand is given by $p_{2}=a-q_{c}-q_{r} \cdot{ }^{16}$ In equilibrium there are no arbitrage opportunities between the spot and the forward market: The forward market price is equal to the spot market price, $p_{1}=p_{2} \cdot{ }^{17}$

Support Schemes: The feed-in tariff and the floating premium ensure that a fixed remuneration, $x \geq 0$, is paid to the renewable producer independently of the market price, whereas a fixed premium adds a fixed amount, $\tau \geq 0$, on top of the market price.

Payoffs: The electricity producer's overall payoff is given by:

$$
\begin{aligned}
& \pi_{c}=p_{1} f_{c}+p_{2}\left(q_{c}-f_{c}\right)-c q_{c} \\
& \pi_{r}= \begin{cases}x q_{r} & (\text { feed-in tariff or floating premium) } \\
p_{1} f_{r}+p_{2}\left(q_{r}-f_{r}\right)+\tau q_{r} & \text { (fixed premium) }\end{cases}
\end{aligned}
$$

The conventional producer's payoff consists of forward market revenues (first summand), spot market revenues (second summand) and production costs (third summand). The renewable producer's payoff depends on the support scheme in place. Under a feed-in tariff or floating premium, the renewable producer receives the fixed remuneration $x$ on output. Under a fixed premium scheme the fixed amount $\tau$ is added to the market price. If $q_{c}<f_{c}$ or $q_{r}<f_{r}$, producers are selling more on the forward market than they actually produce and need to buy the shortfall on the spot.

Because there are no arbitrage opportunities between the spot and the forward market in equilibrium (i.e. $p_{1}=p_{2}=a-q_{c}-q_{r}$ ), overall payoffs can be written

\footnotetext{
${ }^{16}$ Indeed $p_{2}=a-f_{c}-f_{r}-\left(q_{c}-f_{c}\right)-\left(q_{r}-f_{r}\right)=a-q_{c}-q_{r}$.

${ }^{17}$ As long as prices in the two markets are different, competitive speculators buy (sell) forward positions in the first stage and sell (buy) them in the second stage at a higher (lower) price. In equilibrium the two prices are equal.
} 
as:

$$
\begin{aligned}
& \pi_{c}=\left(a-q_{c}-q_{r}-c\right) q_{c} \\
& \pi_{r}= \begin{cases}x q_{r} & \text { (feed-in tariff or floating premium) } \\
\left(a-q_{c}-q_{r}+\tau\right) q_{r} & \text { (fixed premium) }\end{cases}
\end{aligned}
$$

For ease of representation, in the remainder I call spot market payoffs the additional payoffs once forward quantities are locked in:

$$
\begin{aligned}
& \pi_{c, 2}=\left(a-q_{c}-q_{r}\right)\left(q_{c}-f_{c}\right)-c q_{c} \\
& \pi_{r, 2}= \begin{cases}x\left(q_{r}-f_{r}\right) & \text { (feed-in tariff or floating premium) } \\
\left(a-q_{c}-q_{r}+\tau\right)\left(q_{r}-f_{r}\right) & \text { (fixed premium) }\end{cases}
\end{aligned}
$$

Competition: Equilibrium prices are used as a proxy to measure competition in the market.

I am considering subgame perfect equilibria in the spirit of Selten (1975) and solve the game by backward induction. I first derive the equilibria in the spot market (second stage), which are a function of the number of contracts that have been sold on the forward market (first stage). Afterwards, I solve for subgame perfect equilibria in the forward market, by incorporating the second stage equilibrium quantities into the overall profit functions (i.e. assuming that players anticipate to play equilibrium in the spot market).

\section{Feed-in tariff and floating premium}

Under a feed-in tariff, the renewable producer is granted a fixed amount, $x \geq 0$, for any unit of electricity produced. Because a floating premium aims at complementing the market price by a variable subsidy that guarantees a fixed remuneration as well, its effect on producer strategies in the wholesale market are the same as long as the remuneration is non-negative. The analysis of the two support schemes is therefore carried out jointly.

\subsection{Production stage ( $t=2)$}

In stage 2 , forward positions, $f_{c}$ and $f_{r}$, are observed. The conventional producer chooses production quantities so as to maximize his spot market payoff given the spot market price he faces.

$$
\begin{array}{ll}
\max _{q_{c}} & \pi_{c, 2}=\max _{q_{c}}\left[\left(a-q_{c}-q_{r}\right)\left(q_{c}-f_{c}\right)-c q_{c}\right] \\
\text { s.t. } & q_{c} \geq 0
\end{array}
$$


The renewable electricity producer maximizes his spot market payoff given the remuneration he faces. Because his production depends on the amount of renewable energy that is available, he is subject to a constraint.

$$
\begin{array}{ll}
\max _{q_{r}} & \pi_{r, 2}=\max _{q_{r}}\left[x\left(q_{r}-f_{r}\right)\right] \\
\text { s.t. } & k \geq q_{r} \geq 0
\end{array}
$$

Optimal strategies in stage 2 are given in the following lemma.

Lemma 1. Under a feed-in tariff or floating premium, optimal strategies in stage 2 are given by:

$$
\begin{aligned}
& q_{c}^{*}\left(f_{c}, f_{r}\right)=\max \left\{0 ; \frac{1}{2}\left(a-k-c+f_{c}\right)\right\} \\
& q_{r}^{*}\left(f_{c}, f_{r}\right)=k
\end{aligned}
$$

There are two equilibria in the spot market: For a sufficiently high conventional forward position, that is $f_{c} \geq c-a+k$, there is an interior equilibrium, in which both firms produce. Otherwise, there is a renewable monopoly.

In the interior equilibrium, conventional production is increasing in the conventional producer's own forward position. As argued first by Allaz and Vila (1993), this reflects the strategic advantage of using a forward market at the expense of the competitor: A short position on the forward market represents a commitment to production. Producing more decreases equilibrium prices and reduces the marginal profitability of spot market sales. However, a producer that sells forward is less price sensitive in the spot market, as inframarginal units are reduced.

Renewable equilibrium production is always flat and affected neither by the forward market nor by conventional production. Because the renewable producer receives a positive fixed remuneration and his marginal cost is zero, he always produces as much as he can.

\subsection{Forward market $(t=1)$}

In stage 1 , given the equilibria played in stage 2, the conventional electricity producer chooses his forward position so as to maximize his overall payoff.

$$
\begin{array}{cl}
\max _{f_{c}} & \pi_{c}=\max _{f_{c}}\left[(p-c) q_{c}\right] \\
\text { s.t. } & q_{c}=q_{c}^{*}\left(f_{c}, f_{r}\right) \\
\text { s.t. } & q_{r}=k \\
\text { s.t. } & p=a-q_{c}-q_{r}
\end{array}
$$

The renewable electricity producer is indifferent to the use of the forward market. As stated in Lemma 1, optimal renewable production does not depend on forward positions.

The following theorem characterizes the subgame perfect equilibria under a feed-in tariff and a floating premium. 


\section{Theorem 1. Equilibrium (Feed-in Tariff or Floating Premium):}

In any subgame perfect equilibrium of the feed-in tariff or floating premium model, the conventional producer does not use the forward market, $f_{c}^{*} F I T=0$, and the renewable producer is indifferent of using it: $f_{r}^{*}$ FIT may take any value. Spot market equilibrium quantities are given by $q_{c}^{*} F I T\left(f_{c}, f_{r}\right)=\frac{1}{2}\left(a-k-c+f_{c}\right)$ and $q_{r}^{*} F I T\left(f_{c}, f_{r}\right)=k$.

The unique subgame perfect equilibrium price is $p^{*}$ FIT $=\frac{1}{2}(a-k+c)$.

Proof.

Given Lemma 1, spot market equilibria only depend on $f_{c}$. Therefore,

$$
\pi_{c}\left(f_{c}\right)= \begin{cases}\frac{1}{4}\left(a-k-c+f_{c}\right)\left(a-k-c-f_{c}\right) & \text { if } f_{c} \geq c-a+k \\ 0 & \text { otherwise }\end{cases}
$$

This profit is maximized at $f_{c}=0>c-a+k$

Theorem 1 adds to the general Allaz and Vila (1993) results. The renewable producer, receiving a fixed remuneration, always produces at the maximum and is indifferent about selling forward contracts to commit to producing. As a consequence, the conventional producer cannot affect renewable production choices. Because he is unable to increase his own production at the expense of his competitor and anticipates the pro-competitive potential of forward sales, he has no incentive to sell forward contracts.

The unique equilibrium price is represented in Figure 1 for all possible realizations of the renewable energy source that is for all different amounts of renewable electricity that might be available. Equilibrium prices are described on the vertical axis and available renewable electricity on the horizontal axis. For comparison, the outcome of a pure conventional monopoly is represented as well.

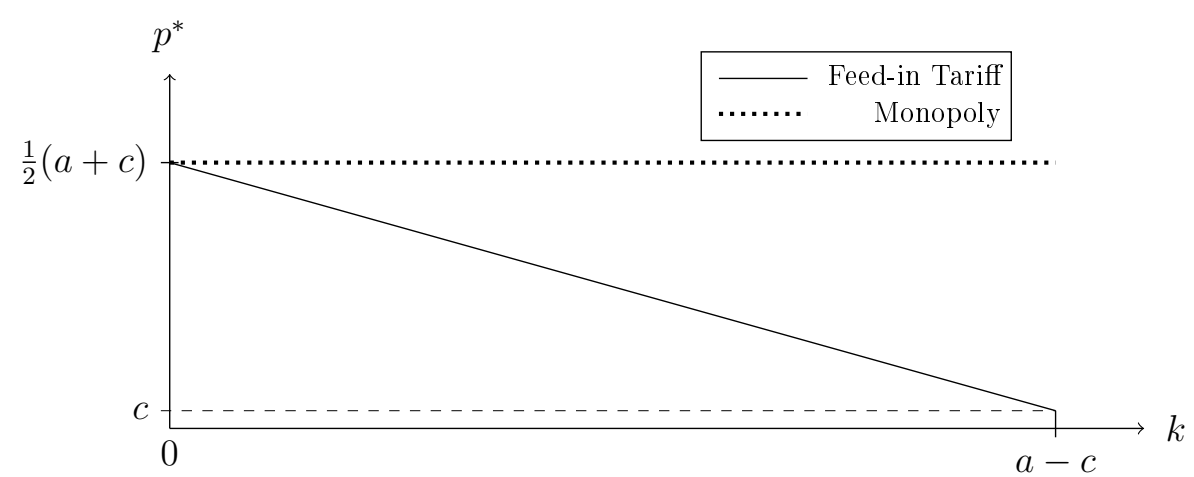

Figure 1: Equilibrium prices under a feed-in tariff and a conventional monopoly. 
Under a feed-in tariff or a floating premium scheme, equilibrium prices decrease proportionally to the amount of available renewable electricity. The reason is that the maximum amount of renewable electricity is always produced. Residual demand for conventional electricity decreases proportionally to $k^{18}$ In a conventional monopoly, prices are not affected by renewable electricity production.

\section{Fixed premium}

Under a fixed premium, the renewable electricity producer receives a fixed amount, $\tau \geq 0$, on top of the wholesale market price.

\subsection{Production stage ( $t=2)$}

In stage 2, the maximization problem of the conventional electricity producer is the same as under the feed-in tariff and given by (1). What changes is the profit of the renewable electricity producer, whose maximization problem is given by

$$
\begin{array}{ll}
\max _{q_{r}} & \pi_{r, 2}=\max _{q_{r}}\left[\left(a-q_{c}-q_{r}+\tau\right)\left(q_{r}-f_{r}\right)\right] \\
\text { s.t. } & k \geq q_{r} \geq 0
\end{array}
$$

Best responses in stage 2 are described in Lemma 2.

Lemma 2. Under a fixed premium, the best responses in stage 2 are given by:

$$
\begin{aligned}
& q_{c}\left(q_{r}, f_{c}, f_{r}\right)=\max \left\{0 ; \frac{1}{2}\left(a-c-q_{r}+f_{c}\right)\right\} \\
& q_{r}\left(q_{c}, f_{c}, f_{r}\right)=\max \left\{0 ; \min \left\{k ; \frac{1}{2}\left(a+\tau-q_{c}+f_{r}\right)\right\}\right\}
\end{aligned}
$$

The best response of each producer is increasing in the producer's own forward position, which reflects the strategic advantage of using the forward market described above. It holds for the conventional and for the renewable electricity producer when the latter does not hit his constraint (i.e, if $k>\frac{1}{2}\left(a+\tau-q_{c}+f_{r}\right)$ ).

These best responses result in six equilibria in the spot market. The formal statement of each equilibrium is given in Appendix A:

- an unconstrained interior equilibrium (UCI), in which both firms produce and the renewable producer is not constrained;

- a constrained interior equilibrium $(\mathrm{CI})$, in which both firms produce and the renewable producer is constrained;

\footnotetext{
${ }^{18}$ If $k \geq a-c$, residual demand for conventional electricity, $a-k$, would equal or fall below the conventional producer's marginal cost, $c$. This case is ruled out by assumption.
} 
- an unconstrained renewable monopoly, in which the conventional producer does not produce and the renewable producer is not constrained;

- a constrained renewable monopoly, in which the conventional producer does not produce and the renewable producer is constrained;

- a conventional monopoly, in which only the conventional producer produces;

- an equilibrium, in which no one produces.

In the remainder, I focus on the two equilibria that will be part of a subgame perfect equilibrium, UCI and CI. Here is their characterization.

Lemma 3. Under a fixed premium, there is

- an unconstrained interior (UCI) equilibrium in the spot market, if $k>\frac{1}{3}(a+$ $\left.2 \tau+c-f_{c}+2 f_{r}\right)$, if $f_{c} \geq-\frac{1}{2}\left(a-\tau-2 c-f_{r}\right)$ and if $f_{r} \geq-\frac{1}{2}\left(a+2 \tau+c-f_{c}\right)$. The corresponding equilibrium strategies of stage 2 are

$$
\begin{aligned}
& q_{c}^{* U C I}\left(f_{c}, f_{r}\right)=\frac{1}{3}\left(a-\tau-2 c+2 f_{c}-f_{r}\right) \\
& q_{r}^{* U C I}\left(f_{c}, f_{r}\right)=\frac{1}{3}\left(a+2 \tau+c-f_{c}+2 f_{r}\right)
\end{aligned}
$$

- a constrained interior equilibrium (CI) in the spot market, if $k \leq \frac{1}{3}(a+2 \tau+$ $\left.c-f_{c}+2 f_{r}\right)$ and if $f_{c} \geq c-a+k$. The corresponding equilibrium strategies of stage 2 are

$$
\begin{aligned}
& q_{c}^{* C I}\left(f_{c}, f_{r}\right)=\frac{1}{2}\left(a-k-c+f_{c}\right) \\
& q_{r}^{* C I}\left(f_{c}, f_{r}\right)=k
\end{aligned}
$$

An unconstrained interior equilibrium arises if the renewable producer has enough energy available to produce his optimal interior quantity, $k>\frac{1}{3}(a+2 \tau+c-$ $f_{c}+2 f_{r}$ ), and when both producers forward so much that deviations to the competitor's monopoly are never profitable. The interior equilibrium is constrained if there is not enough renewable energy available to reach optimal interior production, and when the conventional producer forwards so much that a constrained renewable monopoly can never be an equilibrium.

As in Allaz and Vila (1993), second stage equilibrium strategies in the unconstrained equilibrium are increasing in own forward position and decreasing in the forward position of the competitor. This describes the strategic use of the forward market as a commitment for production at the expense of the competitor. Second stage equilibrium strategies in the constrained equilibrium are the same as in the feed-in tariff case.

There is another strategic effect. The renewable production constraint, $k=$ $\frac{1}{3}\left(a+2 \tau+c-f_{c}+2 f_{r}\right)$ depends on the producers' forward positions. Both electricity 
producers can thus manipulate the constraint by choosing an appropriate forward market strategy. In the next subsection, I show that they have a strategic interest to keep renewable production artificially constrained under certain conditions.

\subsection{Forward market ( $t=1)$}

In stage 1 , given the equilibrium strategies played in stage 2, the two electricity producers choose their forward position so as to maximize their overall payoffs (5) and (6).

$$
\begin{array}{cl}
\max _{f_{c}} & \pi_{c}=(p-c) q_{c} \\
\text { s.t. } & q_{c}=q_{c}^{*}\left(f_{r}, f_{c}\right) \\
\text { s.t. } & q_{r}=q_{r}^{*}\left(f_{c}, f_{r}\right) \\
\text { s.t. } & p=a-q_{c}-q_{r} \\
& \\
\max _{f_{r}} & \pi_{r}=(p+\tau) q_{r} \\
\text { s.t. } & q_{c}=q_{c}^{*}\left(f_{r}, f_{c}\right) \\
\text { s.t. } & q_{r}=q_{r}^{*}\left(f_{c}, f_{r}\right) \\
\text { s.t. } & p=a-q_{c}-q_{r}
\end{array}
$$

For some parameter values, this leads to a unique subgame perfect equilibrium; for others, the subgame perfect equilibria are multiple in the forward market. Different types of equilibria exist: an unconstrained and a constrained interior equilibrium, as well as a mixed strategy equilibrium. Figure 2 represents the equilibria for different realizations of the renewable energy source, $k$, if the premium, $\tau$, is not too generous. ${ }^{19}$

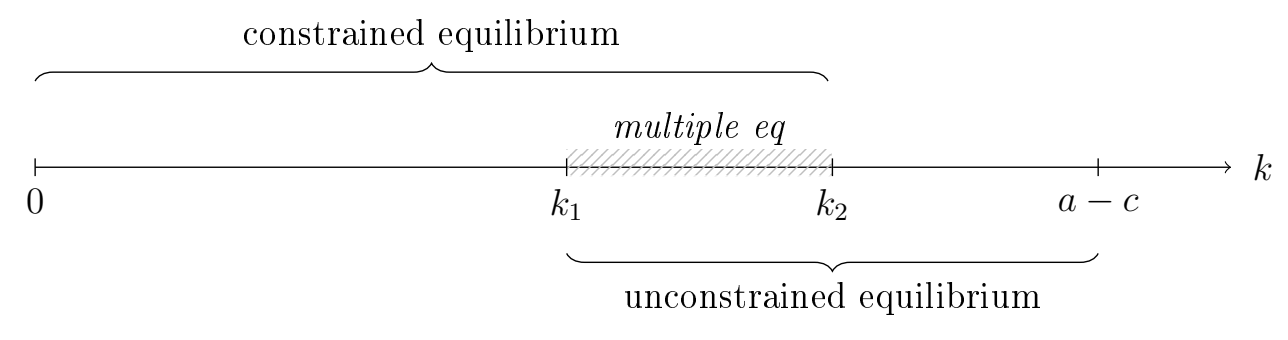

Figure 2: Partitioning of the $k$-space in terms of subgame perfect equilibria for $\tau \leq \bar{\tau}$.

\footnotetext{
${ }^{19}$ If the premium is too generous, the unconstrained equilibrium and the mixed strategy equilibrium do not exist. More details on the level of the premium are below.
} 
Before stating the equilibria in Theorem 2, I will explain their intuition and the conditions for their existence. Which equilibrium arises depends both on the level of renewable energy that is available and on the level of the premium.

First, for relatively high levels of the renewable energy source and premium levels that are not too generous (i.e. RHS of Figure 2), the renewable production constraint does not bind. There is an unconstrained equilibrium, in which the forward market is used strategically. Each producer has a unilateral incentive to take a short position on the forward market to lock in production ex-ante and increase profits at the expense of the competitor.

Second, for relatively low levels of the renewable energy source and premium levels that are not too generous (i.e. LHS of Figure 2), the renewable production constraint binds. There is a constrained equilibrium, in which renewable production is at capacity and the forward market is not used strategically. The renewable producer is indifferent to the use of the forward market. As stated in Lemma 3, optimal renewable production does not depend on forward positions. As a consequence, the conventional producer cannot affect the renewable's production choice to his advantage, and has no incentive to use the forward market.

Third, for premium levels that are very generous (not displayed in Figure 2), the renewable producer always produces at capacity and the forward market is not used strategically for the same reason as above.

Having given the intuition of the two equilibria, I now explain the conditions for both equilibria to be valid (proofs are in Appendix B).

The unconstrained equilibrium is valid if $\tau \leq \bar{\tau}$ and $k>k_{1}$.

Definition 1. The prohibitive premium is $\bar{\tau}=\frac{1}{2}(a-3 c)$.

One of the conditions for the unconstrained equilibrium is $\tau \leq \bar{\tau}$. If $\tau>\bar{\tau}$, the renewable producer's remuneration is so generous that production would always be at maximum capacity. An unconstrained equilibrium could not arise.

Definition 2. The conventional restriction threshold is $k_{1}=a-c-\frac{2 \sqrt{2}}{5}(a-2 \tau-3 c)$.

$k>k_{1}$ is another condition for the unconstrained equilibrium. It ensures that the conventional producer has no incentive to deviate to the constrained equilibrium and that the renewable producer is not constrained.

For example, the conventional restriction threshold is increasing in the level of the premium, $\tau$, because an increase in $\tau$ reduces the conventional producer's relative preference for the unconstrained equilibrium. The intuition is that in the constrained equilibrium renewable production is flat. Therefore, equilibrium prices and conventional production are not affected by $\tau$. In the unconstrained equilibrium, however, a higher $\tau$ increases renewable production and decreases conventional one. Because renewable production is relatively cheaper, its increase 
exceeds the decrease in conventional production in absolute terms. Aggregate electricity production rises and pushes equilibrium prices down. Therefore, increasing $\tau$ reduces the relative loss of the conventional producer in the constrained equilibrium compared to the unconstrained one. Put it differently, the opportunity cost of market power in the unconstrained equilibrium increases with $\tau$.

The constrained equilibrium is valid if $\tau \leq \bar{\tau}$ and $k \leq k_{2}$ or if $\tau>\bar{\tau}$.

Definition 3. The renewable restriction threshold is $k_{2}=\frac{1}{2}(a+2 \tau+c)$. It equals optimal renewable production when the conventional producer plays his constrained equilibrium quantity in stage 1.

If $\tau \leq \bar{\tau}$, the constrained equilibrium arises if and only if $k \leq k_{2}$. For $k>k_{2}$, the renewable production constraint would never bind, as optimal renewable production could be reached for any equilibrium forward position of the conventional producer. As explained above, $\tau>\bar{\tau}$ is a sufficient condition for the constrained equilibrium. In this case, the premium is so generous that renewable production is always at capacity.

Finally, note that if $k \in\left[k_{1} ; k_{2}\right]$ and if $\tau \leq \bar{\tau}$, the two equilibria coexist and none of them Pareto dominates the other. The conventional producer prefers the unconstrained equilibrium and the renewable producer the constrained one. There is a third equilibrium in which producers mix in the forward market. Each forward market equilibrium leads to a unique equilibrium in the spot market.

The following theorem gives the formal statement of the subgame perfect equilibria under a fixed premium.

\section{Theorem 2. Equilibrium (Fixed Premium):}

In the fixed premium model

- if $\tau \leq \bar{\tau}$ and $k>k_{2}$, there is a unique unconstrained subgame perfect equilibrium with forward market equilibrium quantities $f_{c}^{*} U C I=\frac{1}{5}(a-2 \tau-3 c)$ and $f_{r}^{* U C I}=\frac{1}{5}(a+3 \tau+2 c)$. Spot market equilibrium quantities are $q_{c}^{* U C I}=$ $\frac{1}{3}\left(a-\tau-2 c+2 f_{c}-f_{r}\right)$ and $q_{r}^{*} U C I=\frac{1}{3}\left(a+2 \tau+c-f_{c}+2 f_{r}\right)$. The unique subgame perfect equilibrium price is: $p^{* U C I}=\frac{1}{5}(a-2 \tau+2 c)$.

- if $\tau>\bar{\tau}$ or if $\tau \leq \bar{\tau}$ and $k \leq k_{1}$, there is a unique constrained subgame perfect equilibrium with forward market equilibrium quantities $f_{c}^{*} C I=0$ and $f_{r}^{*}$ CI that may take any value. Spot market equilibrium quantities are $q_{c}^{* C I}=$ $\frac{1}{2}\left(a-k-c+f_{c}\right)$ and $q_{r}^{*} C I=k$. The unique subgame perfect equilibrium price is: $p^{* C I}=\frac{1}{2}(a-k+c)$.

- otherwise, there are three equilibria, the two already mentioned and a third equilibrium in which the producers mix in the first stage. 
Having derived equilibrium prices under the fixed premium, I can now analyze their behavior for different realizations of the renewable energy source. Figure 3 describes equilibrium prices on the vertical axis and available renewable electricity on the horizontal axis. For ease of representation, I assume that the unconstrained equilibrium prevails in the range where multiple equilibria exist, if $k \in\left[k_{1} ; k_{2}\right]$, because this is the only situation in which prices under the fixed premium differ from those under the feed-in tariff. Adding the multiplicity of equilibria would not add insight in terms of instrument comparison. For the same reason, it is assumed that $\tau \leq \bar{\tau}$. For comparison, the outcome under the feed-in tariff is represented as well.

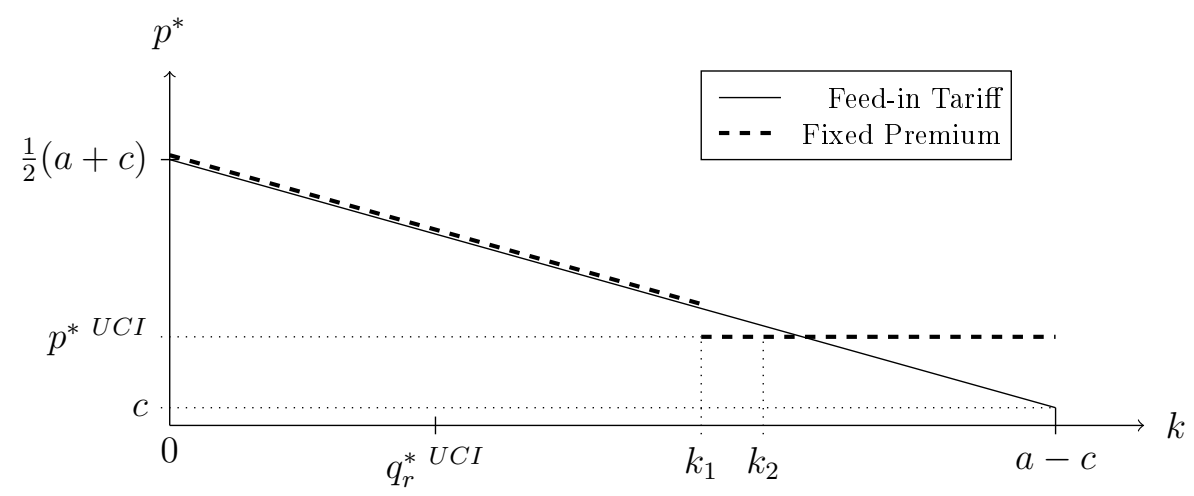

Figure 3: Equilibrium prices under a fixed premium and a feed-in tariff if $\tau \leq \bar{\tau}$.

In the unconstrained equilibrium (at $k>k_{1}$ ), where the renewable producer chooses his optimal quantity and where both producers use the forward market for strategic reason, equilibrium prices under the fixed premium are independent of renewable electricity production and differ from those under the feed-in tariff. This situation is further analyzed in Section 5 .

In the constrained equilibrium (at $k \leq k_{1}$ ), where the renewable producer produces as much as he can and where the forward market is not used strategically, equilibrium prices under the fixed premium equal that under the feed-in tariff. It decreases proportionally to the available amount of renewable electricity, $k$.

Note that for $k \in\left[q_{r}^{*} U C I ; k_{1}\right]$, there is a constrained equilibrium, although the unconstrained equilibrium renewable outcome is technically feasible. In this case, by choosing an appropriate forward market quantity, both electricity producers manipulate the renewable production constraint and extend the occurrence of the constrained equilibrium, in which equilibrium prices are relatively higher. The renewable production constraint acts as a commitment device to withhold production. This additional result relates to work of Grimm and Zoettl (2006), de Frutos 
and Fabra (2012), and Liski and Montero (2014): the presence of asymmetric production constraints reduces the competitive pressure from the forward market, which was predicted by Allaz and Vila (1993).

\section{Analyzing the strategic effects under the fixed premium}

Figure 3 shows equilibrium prices under both the feed-in tariff and the fixed premium scheme. This section studies in more detail how producer strategies are affected by the introduction of the fixed premium in the unconstrained equilibrium (area of the Figure where $k \geq k_{1}$ ). Because the floating premium scheme does not alter equilibrium quantities compared to the feed-in tariff, its effects are not discussed here. In the remainder of this section, I assume that the unconstrained equilibrium prevails where multiple equilibria exist.

\subsection{The fixed premium: increasing market power or competition?}

In the unconstrained equilibrium of the fixed premium model, the strategic behavior of the electricity producers differs in two dimensions from that in the feed-in tariff model. First, the timing of electricity sales varies. Under the feed-in tariff, the forward market is not used strategically. Under the fixed premium, both producers use the spot and the forward market to sell electricity. Second, there is also a difference in the degree of strategic behavior involved in the renewable production decision. Under the feed-in tariff, all available renewable electricity is dumped on the market. Under the fixed premium, the renewable producer is a strategic market participant. Renewable production involves an optimization and is below maximum capacity.

A rigorous comparison of support schemes needs to disentangle the role of the two dimensions. To do so, I use a counterfactual model which differs in only one dimension from each of the two existing schemes. No producer sells electricity on the forward market (close to feed-in tariff) and the renewable producer strategically chooses how much electricity to produce (close to fixed premium). The counterfactual model is equivalent to using the fixed premium model but forcing both producer's forward position to be zero. It results in two Nash equilibria, an unconstrained Nash equilibrium (UNE) if $k \geq k^{U N E}$ and a constrained one (CNE). Their formal statement is given in Appendix D.

I graphically compare equilibrium prices in the counterfactual model with those under the feed-in tariff (Figure 4) and those under the fixed premium (Figure 5). To demonstrate the basic effects, I assume the premium to be zero in this subsection. The level of the premium is further discussed in Subsection 5.2.

(1) Counterfactual model vs feed-in tariff: market power of the duopoly 
Compared to the feed-in tariff, the unconstrained equilibrium of the counterfactual model induces a market power effect (shaded triangle in Figure 4). As a consequence of the renewable electricity producer choosing his production strategically - instead of dumping all available electricity on the market -, the duopoly uses its market power and optimizes aggregate production to keep prices at a relatively high level that is independent of the available amount of the renewable energy source. On the contrary, feed-in tariff prices decrease proportionally to the amount of available renewable electricity.

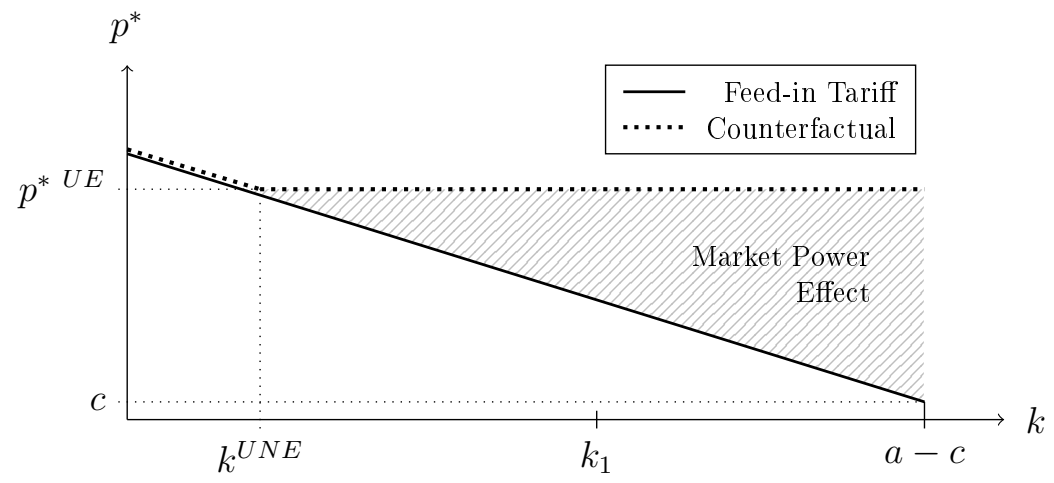

Figure 4: Market power effect of the duopoly if $\tau \leq \bar{\tau}$.

(2) Fixed premium vs counterfactual model: competitive effect of forward market

Because both producers use the forward market, equilibrium prices under the fixed premium scheme are lower than in the unconstrained equilibrium of the counterfactual model. As soon as the unconstrained equilibrium in the fixed premium model is reached (i.e. when $k>k_{1}$ ), both producers start forwarding which increases aggregate electricity production; equilibrium prices jump down (vertical arrow in Figure 5).

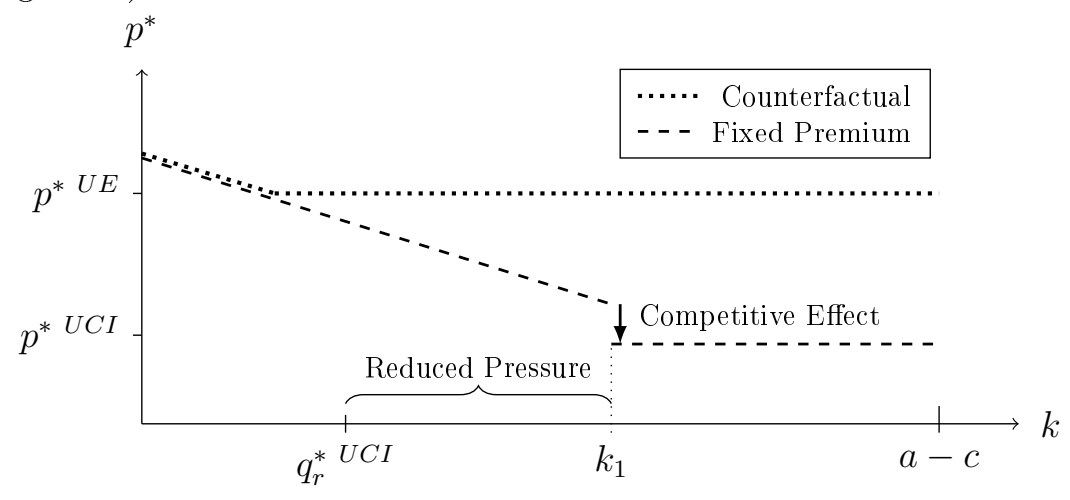

Figure 5: Competitive effects of the forward market if $\tau \leq \bar{\tau}$. 
However, the competitive pressure from the forward market is reduced. The electricity producers manipulate the renewable production constraint and extend the constrained equilibrium of the fixed premium model - in which the procompetitive forward market is not used - to relatively higher levels of available renewable energy although the unconstrained equilibrium would be technically feasible (reduced pressure, $k_{1}>q_{r}^{*} U C I$ ). Still, compared to the unconstrained equilibrium in the counterfactual model, prices in the constrained equilibrium of the fixed premium model are smaller and decrease proportionally to available renewable energy.

These two basic effects, market power and competition, materialize when a feed-in tariff is replaced by a fixed premium. Because they work in opposite directions, the final impact on equilibrium prices depends on which effect dominates; this varies with the available amount of renewable electricity (see Figure 6).

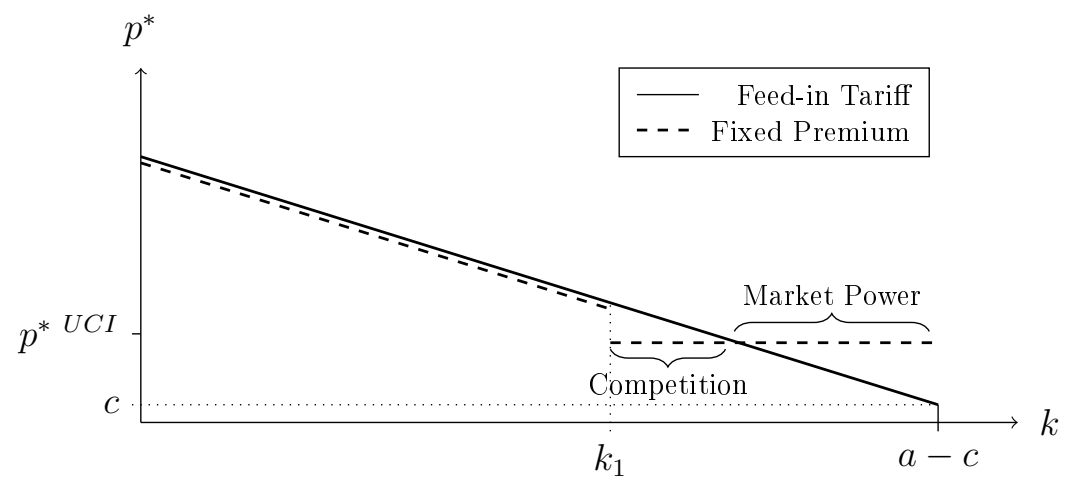

Figure 6: Strategic effect under the fixed premium if $\tau \leq \bar{\tau}$.

If a high level of renewable energy is available, the market power of the duopoly dominates the competitive effect induced by the forward market. Prices under the fixed premium are above feed-in tariff levels. The fixed premium has a negative effect on competition.

If an intermediate level of renewable energy is available, the market power of the duopoly is offset by the forward market's competitive effect. Prices under the fixed premium fall below feed-in tariff levels. The fixed premium has a positive effect on competition. ${ }^{20}$

If renewable production is constrained, prices under the two schemes are the same.

\footnotetext{
${ }^{20}$ The positive effect is reduced when accounting for the multiplicity of equilibria, as the constrained equilibrium extends to levels of $k$ bigger than $k_{1}$. However, it never eliminates the positive effect as it never exceeds the point where the equilibrium prices of the two support schemes intersect. See Figure 3.
} 


\subsection{Which level for the fixed premium?}

The results thus far show that replacing a feed-in tariff by a fixed premium as support scheme for renewable electricity alters producer strategies with two opposing effects: market power and competition. This subsection analyzes how the level of the fixed premium, $\tau$, shapes the results. Broadly speaking, the fixed premium represents a negative marginal cost to renewable electricity. Increasing the level of the premium raises the remuneration of the renewable producer, which affects the equilibria under the fixed premium in two ways.

First, a higher premium mitigates the market power of the electricity duopoly and reduces the price level in the unconstrained equilibrium. With the higher remuneration, renewable production increases and crowds out conventional one. The rise in renewable production per unit increase of the premium exceeds the loss in conventional production in absolute terms. Therefore, more electricity is produced in total, putting pressure on equilibrium prices.

Second, for a higher premium, the opportunity cost of market power is more important. The unconstrained equilibrium becomes relatively less profitable to the conventional producer. With a higher premium both conventional production and prices decrease in the unconstrained equilibrium. Both variables are not affected in the constrained equilibrium. Therefore, the occurrence of the unconstrained equilibrium is reduced to relatively higher levels of the renewable energy source.

There exists a prohibitive premium under which prices under the fixed premium and the feed-in tariff never differ. Remuneration is so generous that renewable electricity production will always be at maximum capacity. There is a constrained equilibrium in the whole parameter range; with prices under both support schemes being the same.

Figure 7 shows equilibrium prices under the fixed premium scheme for $\tau=0$. The arrows indicate the two price effects resulting from an increase in the premium.

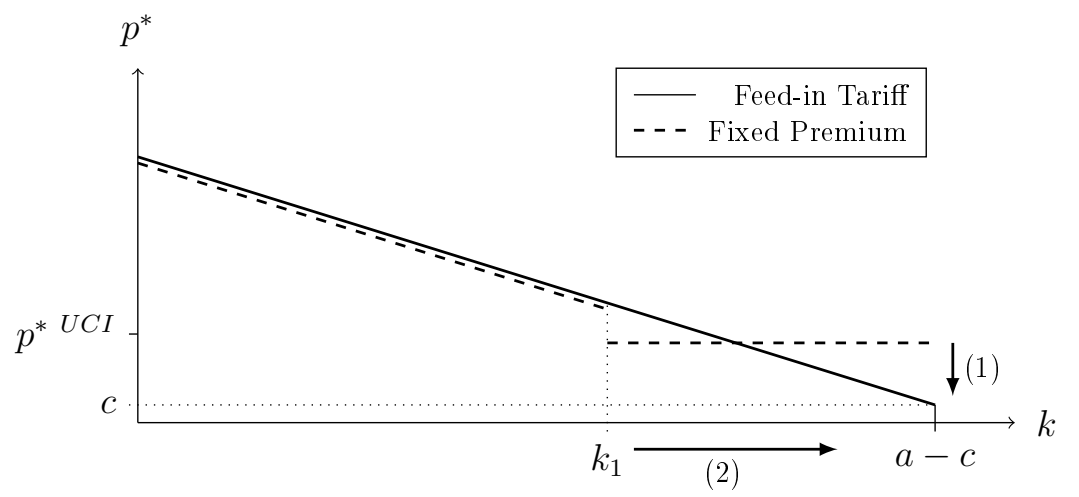

Figure 7: Effects of an increase in the level of the fixed premium if $\tau \leq \bar{\tau}$.

A higher premium reduces the market power of the electricity duopoly in the 
unconstrained equilibrium, by pushing relatively cheaper renewable electricity production. It also reduces the likelihood that prices under both support schemes vary. Setting the premium too high, even eliminates any strategic effect. In the opposite case, the argument goes that for lower premium levels strategic effects are more likely to arise and market power intensifies.

\subsection{Winners and losers of the policy change}

Until now, I have looked at the relative effects on equilibrium prices when a feed-in tariff is replaced by a fixed premium. However, market competition is not the only issue that matters when changing support schemes for renewable electricity. This subsection determines winners and losers of the policy change.

The conventional producer always wins from a switch in support schemes towards the fixed premium if the unconstrained equilibrium is valid. The more renewable electricity is available (i.e. the higher $k$ ), the bigger is the relative gain in conventional profits. This effect is a consequence of the conventional profits' functional form in the two equilibria. Profits decrease proportional to $k$ under a feed-in tariff but are not affected by $k$ in the unconstrained equilibrium of the fixed premium. If the constrained equilibrium is valid, the conventional producer never loses from the switch in support schemes, as conventional profits are the same under a feed-in tariff and fixed premium.

Whether the renewable producer loses or wins in the unconstrained equilibrium of the fixed premium relative to a feed-in tariff depends on the level of renewable energy that is available, and the relationship between the payment under a feed-in tariff, $x$, and under a fixed premium, $\tau .^{21}$ Taking the policy variables $(x$ and $\tau$ ) as given, the renewable producer is more likely to lose under the fixed premium if more renewable electricity is available. The likelihood of losing under the premium increases with the level of $x$ and decreases with the level of $\tau$. If the constrained equilibrium is valid, profits do not change.

Policy makers that aim at increasing electricity production from renewable energy sources, always lose in the unconstrained equilibrium of the fixed premium, because renewable production is withhold (see Section 4).

To conclude, although support schemes are implemented to back electricity production from renewable sources of energy, a switch from the feed-in tariff to the fixed premium seems to favor production from conventional energy sources and puts compliance with European targets at risk.

\footnotetext{
${ }^{21}$ The renewable producer's equilibrium profit under the two support schemes is $\pi_{r}^{U C I}=$ $\frac{2}{25}(a+3 \tau+2 c)^{2}$ and $\pi_{r}^{F I T}=x k$. Therefore, $\pi_{r}^{U C I}<\pi_{r}^{F I T}$ if $x>\frac{2}{25 k}(a+3 \tau+2 c)^{2}$. The likelihood that the renewable producer loses in the unconstrained equilibrium increases with the level of $x$ and decreases with the level of $\tau$ and $k$.
} 


\section{Discussion of results}

Section 5 shows that, when using wholesale equilibrium prices as an indicator for market efficiency, the argumentation of the European Commission has to be refined. Replacing a feed-in tariff by a feed-in premium as support scheme for renewable electricity does not necessarily increase market efficiency. In my model, the relative effect on competition depends on the design of the premium. There is no competitive effect if a floating premium replaces the feed-in tariff because producer strategies are the same under both schemes. If a fixed premium is implemented, the renewable electricity producer becomes a strategic market participant. Whether this leads to more or less competition in the market depends on the amount of the premium and the availability of the renewable energy source.

Taking my model literally shows that introducing a fixed premium may even reduce market efficiency and risks strengthening market power. Market power issues are more likely to arise when renewable energy is abundant, because electricity producers have an incentive and room for maneuver to increase prices. The lower the level of the premium, the stronger and more likely this market power will be.

Because there is a political will to further push renewable electricity production and to do so at lowest cost, we can expect an increase in available renewable energy and a decrease in premium levels in the medium term. My model predicts that market power is strengthened and more likely to occur in such a situation.

As my model describes only a small part of current electricity markets, these results might be affected when a additional market characteristics are considered:

First, a high level of renewable energy may, in some countries, be associated with multiple renewable electricity producers. It is very likely that this alleviates the market power effect, which is emphasized in my duopoly model. Though, the multiplicity of renewable electricity producers will be less of an issue in countries with high amounts of capital intensive offshore wind or concentrated solar power stations, such as Denmark and Spain.

Second, my model treats renewable and conventional electricity production separately, although some producers may actually use both production technologies at the same time. If the conventional producer has access to both the conventional and the renewable technology (dual producer) and if he competes with a single renewable producer, his production incentives are likely to change as follows.

Under a feed-in tariff or a floating premium, renewable electricity receives a fixed and positive remuneration, thus the dual producer will use the renewable technology at full capacity and the conventional one according to residual demand. The equilibrium price will depend on the available amount of renewable electricity and thus the total renewable capacity that is installed. Under a fixed premium, due to the different marginal cost of both technologies, the dual producer has an incentive to produce relatively more with the renewable than the relatively 
expensive conventional technology. A higher premium strengthens this incentive, as it increases the marginal cost difference of both technologies.

In this respect, it is worth noting that there is a current trend for big dual producers in European countries to split renewable and conventional electricity production into different legal entities. ${ }^{22}$ My original model captures this trend by treating conventional and renewable producers separately.

Third, my analysis looks at wholesale electricity markets in the short run and does not consider potential investments in capacity. In the long run, renewable capacity will be endogenous on the support scheme in place. Under a feed-in tariff or a floating premium, a stable remuneration is offered to the renewable electricity producer over a long time horizon, which incentivizes long term investment in renewable capacity. Under the fixed premium, investment in renewable capacity is likely to be smaller for at least two reasons. First, remuneration to renewable electricity depends on equilibrium prices that are not stable over time and thus less predictable. Therefore, incentives to build additional production facilities might be weaker than in a feed-in tariff world. Second, similar to what argue Grimm and Zoettl (2006) and Liski and Montero (2014), my model predicts that the use of the forward market under a fixed-premium depresses prices in the spot market when the unconstrained equilibrium is valid. This may further reduce investment incentives under the fixed premium.

In this respect, note that my analysis does not model the effect of support scheme on consumer prices or public finances. If the financial burden to support renewable energy is higher under the feed-in tariff, the potentially higher renewable capacity under a feed-in tariff will raise the burden on those who pay for the renewable energy support.

Finally, the amount of renewable energy that is available for production depends on nature (e.g. availability of wind and sun) and might not always be predictable the day-ahead. Uncertainty about renewable production could be introduced in the model at the moment where forward contracts are signed and relieved at the moment where production takes place. The renewable producer's exposure to risk is likely to differ with the support scheme in place. Full insurance is provided under a feed-in tariff and floating premium, where the uncertainty about renewable production would translate into a shock to expected residual demand for conventional electricity. Insurance is only partial under a fixed premium, where renewable producers are strategic market participants and likely to reflect the production uncertainty in their market behavior. Such an extension of the model

\footnotetext{
${ }^{22}$ For example, in 2014 and 2015 two of the four big power utilities in Germany, eON and RWE, have announced to split renewable from fossil fuel capacity. Similar strategies are discussed by leading electricity producers in other European countries such as Denmark.
} 
would relate to the work of Adilov (2012) and Knaut and Obermüller (2016). As mentioned above, in such a framework it will be more difficult to disentangle the strategic effects from the producer's attitude towards risk.

\section{Conclusions}

European support schemes for renewable electricity affect the functioning of the wholesale electricity market and are currently revised, with the aim of enhancing competition and market efficiency. Two price-based support schemes are at the center of the debate: feed-in tariffs and feed-in premiums. The latter usually take the form of floating or fixed premiums. I propose a model to analyze both support schemes and their impact on producer strategies and competition in the wholesale electricity market, measured in terms of equilibrium prices.

In my model, replacing the feed-in tariff by a floating premium scheme has no effect on producer strategies or competition. Using a fixed premium scheme instead transforms renewable producers into strategic market participants. This may alter producer strategies with two opposing effects on competition. On the one hand, electricity producers unilaterally have an incentive to sell production commitments on the forward market, which decreases wholesale prices. On the other hand, renewable and conventional electricity producers in the aggregate withhold production so as to keep prices at high levels.

The net effect on wholesale market competition depends on the amount of renewable energy that is available. For high levels of renewable energy, the market power of the duopoly dominates the competitive effect induced by the forward market. As a consequence, the fixed premium would lower competition relative to the feed-in tariff. Because there is a political will to push renewable electricity production, this situation may occur more often in the future. Also the level of the premium plays an important role. Reducing the premium may strengthen the market power of the electricity oligopoly. ${ }^{23}$

These results are important in current discussions about the design of pricebased support schemes for renewable electricity. Rather than justifying a push towards the feed-in premium by solely focusing on the positive effect induced by the enhanced reactivity of renewable producers to market forces, we need to consider that the reactivity of renewable producers may translate into strategic behavior.

\footnotetext{
${ }^{23}$ My model does not look at the effect of support schemes on consumer prices. Higher premium levels translate into higher cost for support of renewable electricity that may ultimately be passed on to electricity consumers or taxpayers.
} 


\section{Acknowledgments}

I am extremely grateful to Estelle Cantillon for very useful comments and discussion and thank Natalia Fabra, Elisabetta Cornago, Isis Durrmeyer and seminar participants of the Environmental and Energy Economics seminar at ECARES (Université libre de Bruxelles), the MaCCI-TSE Competition Economics Workshop, the Cologne International Energy Summer and the audience of the $10^{\text {th }}$ International Conference on the European Energy Market. I also thank two anonymous referees for their comments and suggestions, which helped to significantly improve the paper. Financial support from the Belgian National Science Foundation (FNRS) is gratefully acknowledged.

\section{Bibliography}

Adilov, N. (2012). Strategic use of forward contracts and capacity constraints. International Journal of Industrial Organization, 30(2):164-173.

Allaz, B. and Vila, J.-L. (1993). Cournot competition, forward markets and efficiency. Journal of Economic Theory, 59:1-16.

Amundsen, E. S. and Bergman, L. (2012). Green Certificates and Market Power on the Nordic Power Market. The Energy Journal, 33(2):101-117.

Amundsen, E. S. and Mortensen, J. B. (2001). The Danish Green Certificate System: some simple analytical results. Energy Economics, 23:489-509.

Bagwell, K. (1995). Commitment and Observability in Games. Games and Economic Behavior, 8:271-280.

Borenstein, S. and Bushnell, J. (1999). An Empirical Analysis of the Potential for Market Power in California's Electricity Industry. The Journal of Industrial Economics, 47(3):285-323.

Borenstein, S., Bushnell, J., Knittel, C. R., and Wolfram, C. (2008). Inefficiencies and Market Power in Financial Arbitrage: A study of California's Electricity Markets. The Journal of Industrial Economics, LVI(2).

Borenstein, S., Bushnell, J. B., and Wolak, F. A. (2002). Measuring Market Inefficiencies in California's Restructured Wholesale Electricity Market. American Economic Review, 92(5):1376-1405.

Brandts, J., Pezanis-Christou, P., and Schram, A. (2008). Competition with forward contracts: A laboratory analysis motivated by electricity market design. The Economic Journal, 118(2008):192-214. 
Bushnell, B. J. B., Mansur, E. T., and Saravia, C. (2008). Vertical Arrangements, Market Structure, and Competition: An Analysis of Restructured US Electricity Markets. American Economic Review, 98(1):237-266.

Bushnell, J. (2007). Oligopoly equilibria in electricity contract markets. Journal of Regulatory Economics, 32(3):225-245.

de Frutos, M.-A. and Fabra, N. (2012). How to allocate forward contracts: The case of electricity markets. European Economic Review, 56(3):451-469.

European Commission (2012a). Renewable Energy: a major player in the European energy market, $\mathrm{COM}(2012) 271$.

European Commission (2012b). Staff working document, SWD(2012)164.

European Commission (2014a). A policy framework for climate and energy in the period from 2020 to $2030, \operatorname{COM}(2014) 15$.

European Commission (2014b). Guidelines on State aid for environmental protection and energy 2014-2020, 2014/C 200/01.

European Council (2014). Conclusions on 2030 Climate and Energy Policy Framework, SN 79/14.

Fabra, N., Glachant, J.-M., Green, R., von Hirschhausen, C., Leprich, U., Neuhoff, K., Newbery, D., Lorenzoni, A., Mitchell, C., and del Río, P. (2014). Open letter of European economists on market premiums to Commissioner Günther Oettinger and Joaquin Almunia. (24 March).

Fabra, N. and Toro, J. (2005). Price wars and collusion in the Spanish electricity market. International Journal of Industrial Organization, 23(3-4):155-181.

Ferreira, J. L. (2003). Strategic interaction between futures and spot markets. Journal of Economic Theory, 108:141-151.

Ferreira, J. L., Kujal, P., and Rassenti, S. (2016). Multiple Openings and Competitiveness of Forward Markets: Experimental Evidence. PLoS ONE, 11(7).

Fischer, C. (2010). Renewable Portfolio Standards: When Do They Lower Energy Prices? The Energy Journal, 31(1):101-119.

Grimm, V. and Zoettl, G. (2006). Access to Commitment Devices Reduces Investment Incentives in Oligopoly. University of Cologne Working Paper Series in Economics, No. 25. 
Holmberg, P. (2011). Strategic forward contracting in the wholesale electricity market. Energy Journal, 31:169-202.

Hughes, J. S. and Kao, J. L. (1997). Strategic forward contracting and observability. International Journal of Industrial Organization, 16:121-133.

Jensen, S. G. and Skytte, K. (2002). Interactions between the power and green certificate markets. Energy Policy, 30:425-435.

Joskow, P. L. and Kahn, E. (2002). A Quantitative Analysis of Pricing Behavior in California's Wholesale Electricity Market During Summer 2000. The Energy Journal, 23(4):1-35.

Kamat, R. and Oren, S. S. (2004). Two-settlement Systems for Electricity Markets under Network Uncertainty and Market Power. Journal of Regulatory Economics, 25(1):5-37.

Knaut, A. and Obermüller, F. (2016). How to Sell Renewable Electricity - Interactions of the Intraday and Day-ahead Market Under Uncertainty. EWI Working Paper, No 16/04.

Le Coq, C. and Orzen, H. (2006). Do forward markets enhance competition? Journal of Economic Behavior \& Organization, 61(3):415-431.

Liski, M. and Montero, J.-P. (2006). Forward trading and collusion in oligopoly. Journal of Economic Theory, 131(1):212-230.

Liski, M. and Montero, J.-P. (2014). Forward trading in exhaustible-resource oligopoly. Resource and Energy Economics, 37:122-146.

Mahenc, P. and Salanié, F. (2004). Softening competition through forward trading. Journal of Economic Theory, 116:282-293.

Mansur, E. T. (2007). Upstream Competition and Vertical Integration in Electricity Markets. Journal of Law and Economics, 50:125-156.

Powell, A. (1993). Trading Forward in an Imperfect Market: The Case of Electricity in Britain. The Economic Journal, 103(417):444-453.

Sáenz de Miera, G., del Río González, P., and Vizcaíno, I. (2008). Analysing the impact of renewable electricity support schemes on power prices: The case of wind electricity in Spain. Energy Policy, 36(9):3345-3359.

Schmalensee, R. (2011). Evaluating Policies to Increase Electricity Generation from Renewable Energy. Review of Environmental Economics and Policy, $6(1): 45-64$. 
Selten, R. (1975). Reexamination of the Perfectness Concept for Equilibrium Points in Extensive Games. International Journal of Game Theory, 4(1):2555.

Sensfuß, F., Ragwitz, M., and Genoese, M. (2008). The merit-order effect: A detailed analysis of the price effect of renewable electricity generation on spot market prices in Germany. Energy Policy, 36(8):3086-3094.

Tanaka, M. and Chen, Y. (2013). Market power in renewable portfolio standards. Energy Economics, 39:187-196.

Twomey, P. and Neuhoff, K. (2010). Wind power and market power in competitive markets. Energy Policy, 38(7):3198-3210.

van Koten, S. and Ortmann, A. (2013). Structural versus behavioral remedies in the deregulation of electricity markets: An experimental investigation motivated by policy concerns. European Economic Review, 64:256-265.

Weigt, H. and von Hirschhausen, C. (2008). Price formation and market power in the German wholesale electricity market in 2006. Energy Policy, 36(11):42274234 .

Wolak, F. A. (2000). An Empirical Analysis of the impact of Hedge Contracts on Bidding Behavior in a Competitive Electricity Market. International Economic Journal, 14(2):1-39.

Wolak, F. A. and Patrick, R. H. (2001). The Impact of Market Rules and Market Structure on the Price Determination Process in the England and Wales Electricity Market. NBER Working Paper Series, WP 8248.

Wolfram, C. D. (1999). Measuring Duopoly Power in the British Electricity Spot Market. American Economic Review, 89(4):805-826. 


\section{Appendices}

\section{Appendix A. Stage 2 equilibria under a fixed premium}

The best responses given in Lemma 2 (main text) result in six equilibria of the second stage game. Figure A.8 represents graphically these six equilibria for all possible stage 1 actions, that is for any $f_{c^{-}} f_{r}$-pair. Their characterization is given in Lemma 4 to 9.

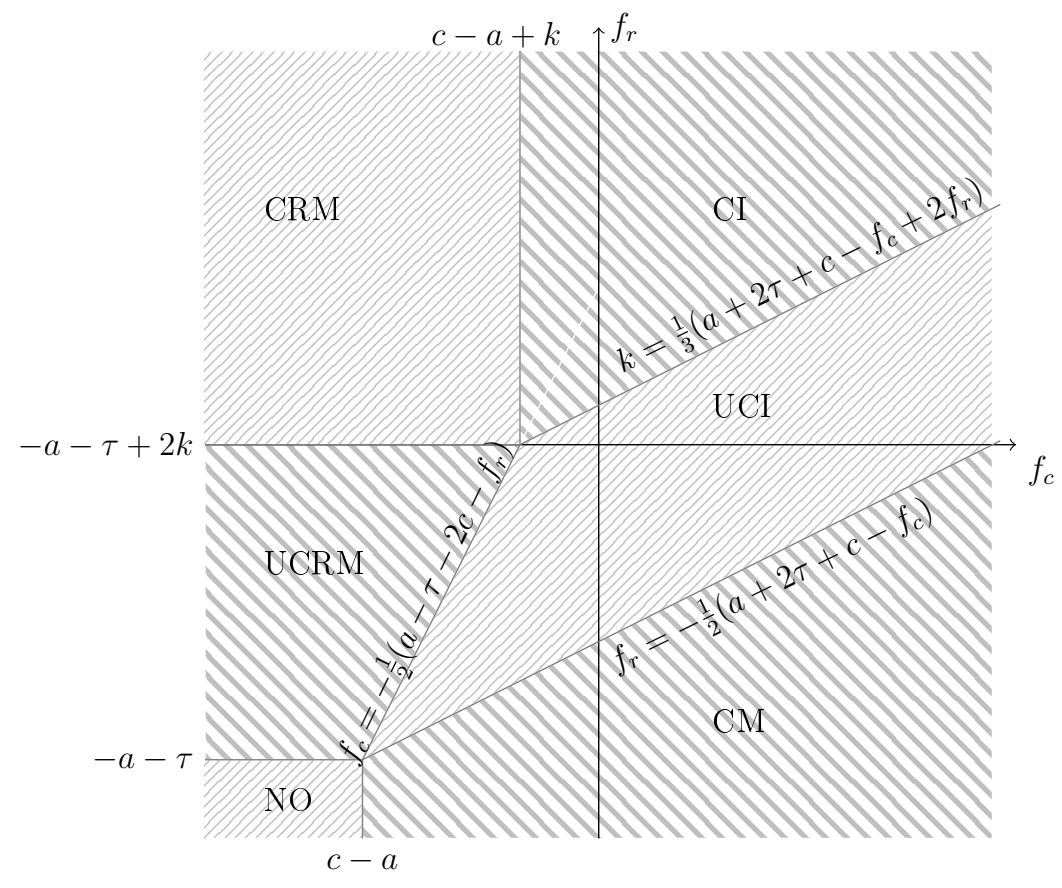

Figure A.8: Stage 2 equilibria under the fixed premium.

Lemma 4. Unconstrained interior equilibrium (UCI):

Both firms produce and the renewable producer is not constrained if

$$
\begin{aligned}
& k>\frac{1}{3}\left(a+2 \tau+c-f_{c}+2 f_{r}\right) \\
& f_{c} \geq-\frac{1}{2}\left(a-\tau-2 c-f_{r}\right) \\
& f_{r} \geq-\frac{1}{2}\left(a+2 \tau+c-f_{c}\right)
\end{aligned}
$$

For all $f_{c}$ - $f_{r}$-pairs for which inequalities (A.1) are satisfied, stage 2 equilibrium strategies are given by $q_{c}^{*} U C I\left(f_{c}, f_{r}\right)=\frac{1}{3}\left(a-\tau-2 c+2 f_{c}-f_{r}\right)$ and $q_{r}^{*} U C I\left(f_{c}, f_{r}\right)=$ $\frac{1}{3}\left(a+2 \tau+c-f_{c}+2 f_{r}\right)$.

Equilibrium profits are $\pi_{c}^{*} U C I\left(f_{c}, f_{r}\right)=\frac{1}{9}\left(a-\tau-f_{c}-f_{r}-2 c\right)\left(a-\tau+2 f_{c}-f_{r}-2 c\right)$ and $\pi_{r}^{*} U C I\left(f_{c}, f_{r}\right)=\frac{1}{9}\left(a+2 \tau-f_{r}-f_{c}+c\right)\left(a+2 \tau+2 f_{r}-f_{c}+c\right)$. 
There is an unconstrained interior equilibrium in stage 2, if the renewable producer has enough energy available to produce his optimal interior quantity, $k>$ $\frac{1}{3}\left(a+2 \tau+c-f_{c}+2 f_{r}\right)$, and when both producers forward so much that deviations to the competitor's monopoly are never profitable, $f_{c} \geq-\frac{1}{2}\left(a-\tau-2 c-f_{r}\right)$ and $f_{r} \geq-\frac{1}{2}\left(a+2 \tau+c-f_{c}\right)$.

Proof. Given the best responses stated in Lemma 2:

For $q_{r}\left(q_{c}, f_{c}, f_{r}\right)=\frac{1}{2}\left(a+\tau-q_{c}+f_{r}\right) \Rightarrow q_{c}^{*}\left(q_{r}, f_{c}, f_{r}\right) \geq 0$ iff $f_{c} \geq-\frac{1}{2}\left(a-\tau-2 c-f_{r}\right)$. For $q_{c}\left(q_{r}, f_{c}, f_{r}\right)=\frac{1}{2}\left(a-c-q_{r}+f_{c}\right) \Rightarrow q_{r}^{*}\left(q_{c}, f_{c}, f_{r}\right) \geq 0$ iff $f_{r} \geq-\frac{1}{2}\left(a+2 \tau+c-f_{c}\right)$ and $q_{r}^{*}\left(q_{c} f_{c}, f_{r}\right)<k$ iff $\frac{1}{3}\left(a+2 \tau+c-f_{c}+2 f_{r}\right)>k$.

Lemma 5. Constrained interior equilibrium (CI):

Both firms produce and the renewable producer is constrained if

$$
\begin{aligned}
& k \leq \frac{1}{3}\left(a+2 \tau+c-f_{c}+2 f_{r}\right) \\
& f_{c} \geq c-a+k
\end{aligned}
$$

For all $f_{c^{-}} f_{r}$-pairs for which inequalities (A.2) are satisfied, stage 2 equilibrium strategies are given by $q_{c}^{*} C I\left(f_{c}, f_{r}\right)=\frac{1}{2}\left(a-k+f_{c}-c\right)$ and $q_{r}^{*} C I\left(f_{c}, f_{r}\right)=k$.

Equilibrium profits are $\pi_{c}^{*} C I\left(f_{c}, f_{r}\right)=\frac{1}{4}\left(a-k-f_{c}-c\right)\left(a-k+f_{c}-c\right)$ and $\pi_{r}^{*} C I\left(f_{c}, f_{r}\right)=\frac{1}{2}\left(a+2 \tau-k-f_{c}+c\right) k$.

There is a constrained interior equilibrium in stage 2 , if there is not enough renewable energy available to reach optimal interior production, $k \leq \frac{1}{3}(a+2 \tau+$ $\left.c-f_{c}+2 f_{r}\right)$, and when the conventional producer forwards so much that deviating to the constrained renewable monopoly is not profitable, $f_{c} \geq c-a+k$.

Proof. Given the best responses stated in Lemma 2:

For $q_{r}\left(q_{c}, f_{c}, f_{r}\right)=k \Rightarrow \frac{1}{2}\left(a-c-q_{r}+f_{c}\right) \geq 0$ iff $f_{c} \geq c-a+k$.

For $q_{c}\left(q_{r}, f_{c}, f_{r}\right)=\frac{1}{2}\left(a-c-q_{r}+f_{c}\right) \Rightarrow q_{r}^{*}\left(q_{c}, f_{c}, f_{r}\right) \geq k$ iff $k \leq \frac{1}{3}\left(a+2 \tau+c-f_{c}+\right.$ $\left.2 f_{r}\right)=q_{r}^{*} U C I\left(f_{c}, f_{r}\right)$. By definition $k>0$.

\section{Lemma 6. Unconstrained renewable monopoly (UCRM):}

The conventional producer does not produce and the renewable producer is not constrained if

$$
\begin{aligned}
& k>\frac{1}{2}\left(a+\tau+f_{r}\right) \\
& f_{c}<-\frac{1}{2}\left(a-\tau-2 c-f_{r}\right) \\
& f_{r} \geq-a-\tau
\end{aligned}
$$

For all $f_{c^{-}} f_{r}$-pairs for which inequalities (A.3) are satisfied, stage 2 equilibrium strategies are given by $q_{c}^{*} U C R M\left(f_{c}, f_{r}\right)=0$ and $q_{r}^{*} U C R M\left(f_{c}, f_{r}\right)=\frac{1}{2}\left(a+\tau+f_{r}\right)$. Equilibrium profits are $\pi_{c}^{* U C R M}\left(f_{c}, f_{r}\right)=0$ and $\pi_{r}^{* U C R M}\left(f_{c}, f_{r}\right)=\frac{1}{4}\left(a+\tau-f_{r}\right)(a+$ $\tau+f_{r}$. 
There is an unconstrained renewable monopoly in stage 2, if the renewable producer has enough energy available to produce his optimal monopoly quantity, $k>\frac{1}{2}\left(a+\tau+f_{r}\right)=q_{r}^{* U C R M}\left(f_{c}, f_{r}\right)$, if he forwards so much that quitting the market will never be profitable, $f_{r} \geq-a-\tau$, and if the conventional producer does not forward enough to make deviations to the unconstrained interior equilibrium profitable $f_{c}<-\frac{1}{2}\left(a-\tau-2 c-f_{r}\right)$.

Proof. Given the best responses stated in Lemma 2:

For $q_{r}\left(q_{c}, f_{c}, f_{r}\right)=\frac{1}{2}\left(a+\tau-q_{c}+f_{r}\right) \Rightarrow 0>q_{c}^{*}\left(q_{r}, f_{c}, f_{r}\right)$ iff $f_{c}<-\frac{1}{2}\left(a-\tau-2 c-f_{r}\right)$. For $q_{c}\left(q_{r}, f_{c}, f_{r}\right)=0 \Rightarrow \frac{1}{2}\left(a+\tau-q_{c}+f_{r}\right) \geq 0$ iff $f_{r} \geq-a-\tau$ and $\frac{1}{2}\left(a+\tau-q_{c}+f_{r}\right)<k$ iff $k>\frac{1}{2}\left(a+\tau+f_{r}\right)$.

Lemma 7. Constrained renewable monopoly (CRM):

The conventional producer does not produce and the renewable producer is constrained if

$$
\begin{aligned}
& k \leq \frac{1}{2}\left(a+\tau+f_{r}\right) \\
& f_{c}<c-a+k
\end{aligned}
$$

For all $f_{c^{-}} f_{r}$-pairs for which inequalities (A.4) are satisfied, stage 2 equilibrium strategies are given by $q_{c}^{*} C R M\left(f_{c}, f_{r}\right)=0$ and $q_{r}^{*} C R M\left(f_{c}, f_{r}\right)=k$.

Equilibrium profits are $\pi_{c}^{* C R M}\left(f_{c}, f_{r}\right)=0$ and $\pi_{r}^{* C R M}\left(f_{c}, f_{r}\right)=(a+\tau-k) k$.

There is a constrained renewable monopoly in stage 2, if there is not enough renewable energy available to reach the optimal renewable monopoly production, $k \leq \frac{1}{2}\left(a+\tau+f_{r}\right)=q_{r}^{*} \operatorname{UCRM}\left(f_{c}, f_{r}\right)$, and when the conventional producer does not forward enough to make deviations to the constrained interior equilibrium profitable, $f_{c}<c-a+k$.

Proof. Given the best responses stated in Lemma 2:

For $q_{r}\left(q_{c}, f_{c}, f_{r}\right)=k \Rightarrow 0>\frac{1}{2}\left(a-c-q_{r}+f_{c}\right)$ iff $f_{c}<c-a+k$.

For $q_{c}\left(q_{r}, f_{c}, f_{r}\right)=0 \Rightarrow \frac{1}{2}\left(a+\tau-q_{c}+f_{r}\right) \geq k$ iff $k \leq \frac{1}{2}\left(a+\tau+f_{r}\right)$. By definition $k>0$.

\section{Lemma 8. Conventional monopoly (CM):}

Only the conventional producer produces if

$$
\begin{aligned}
& f_{c} \geq c-a \\
& f_{r}<-\frac{1}{2}\left(a+2 \tau+c-f_{c}\right)
\end{aligned}
$$

For all $f_{c^{-}} f_{r}$-pairs for which inequalities (A.5) are satisfied, stage 2 equilibrium strategies are given by $q_{c}^{*} C M\left(f_{c}, f_{r}\right)=\frac{1}{2}\left(a-c+f_{c}\right)$ and $q_{r}^{*} C M\left(f_{c}, f_{r}\right)=0$. Equilibrium profits are $\pi_{c}^{*} C M\left(f_{c}, f_{r}\right)=\frac{1}{4}\left(a-f_{c}-c\right)\left(a+f_{c}-c\right)$ and $\pi_{r}^{*} C M\left(f_{c}, f_{r}\right)=$ 0 . 
There is a conventional monopoly in stage 2, when the conventional producer forwards so much that quitting the market will never be profitable, $f_{c} \geq c-a$, and the renewable producer does not forward enough to make deviations to the unconstrained interior equilibrium profitable, $f_{r}<-\frac{1}{2}\left(a+2 \tau+c-f_{c}\right)$.

Proof. Given the best responses stated in Lemma 2:

For $q_{r}\left(q_{c}, f_{c}, f_{r}\right)=0 \Rightarrow \frac{1}{2}\left(a-c-q_{r}+f_{c}\right) \geq 0$ iff $f_{c} \geq c-a$.

For $q_{c}\left(q_{r}, f_{c}, f_{r}\right)=\frac{1}{2}\left(a-c-q_{r}+f_{c}\right) \Rightarrow 0>q_{r}^{*}\left(q_{c}, f_{c}, f_{r}\right)$ iff $f_{r}<-\frac{1}{2}\left(a+2 \tau+c-f_{c}\right)$. By definition, $f_{r}<\frac{1}{2}\left(f_{c}-a-c-2 \tau\right) \Rightarrow \frac{1}{3}\left(a+2 \tau+c-f_{c}+2 f_{r}\right)<k$.

Lemma 9. No one produces (NO) if

$$
\begin{aligned}
& f_{c}<c-a \\
& f_{r}<-a-\tau
\end{aligned}
$$

For all $f_{c^{-}} f_{r}$-pairs for which inequalities (A.6) are satisfied, stage 2 equilibrium strategies are given by $q_{c}^{*}{ }^{N O}\left(f_{c}, f_{r}\right)=q_{r}^{*}{ }^{N O}\left(f_{c}, f_{r}\right)=0$. Equilibrium profits are $\pi_{c}^{* N O}\left(f_{c}, f_{r}\right)=\pi_{r}^{*} N O\left(f_{c}, f_{r}\right)=0$.

There is an equilibrium in stage 2 where no one produces, when the forward positions of both producers are so small (even negative) that deviations to either competitor's monopoly are never profitable, $f_{c}<c-a$ and $f_{r}<-a-\tau$.

Proof. Given the best responses stated in Lemma 2:

For $q_{r}\left(q_{c}, f_{c}, f_{r}\right)=0 \Rightarrow 0>\frac{1}{2}\left(a-c-q_{r}+f_{c}\right)$ iff $f_{c}<c-a$.

For $q_{c}\left(q_{r}, f_{c}, f_{r}\right)=0 \Rightarrow 0>\frac{1}{2}\left(a-c-q_{r}+f_{c}\right)$ iff $f_{r}<-a-\tau$. By definition, $f_{r}<-a-\tau \Rightarrow \frac{1}{2}\left(a-c-q_{r}+f_{c}\right)<k$.

\section{Appendix B. Proof of definitions}

The prohibitive premium: $\bar{\tau}=\frac{1}{2}(a-3 c)$

If $\tau>\bar{\tau}$ optimal renewable production in the unconstrained equilibrium increases up to a level that lies outside the parameter range considered by the model: $\tau>\bar{\tau} \Rightarrow q_{r}^{*} U C I>a-c$.

The conventional restriction threshold: $k_{1}=a-c-\frac{2 \sqrt{2}}{5}(a-2 \tau-3 c)$

If $k>k_{1}$ the conventional producer has no incentive to deviate to the constrained equilibrium: $k>k_{1} \Rightarrow \pi_{c}^{*} U C I>\pi_{c}^{*} C I$. In this case, given the level of $\tau$ in the unconstrained equilibrium, the renewable producer will be unconstrained: $\tau \leq \bar{\tau} \Rightarrow k_{1} \geq q_{r}^{*} U C I$.

The renewable restriction threshold: $k_{2}=\frac{1}{2}(a+2 \tau+c)$

If $k \leq k_{2}$ the renewable production constraint binds when the conventional producer plays his constrained equilibrium strategy in stage 1:

$k \leq k_{2} \Rightarrow q_{r}^{*} U C I\left(f_{c}^{*} C I, f_{r}^{U C I}\left(f_{c}^{*} C I\right)\right) \geq k$. 


\section{Appendix C. Proof of Theorem 2}

\section{Proof.}

To prove Theorem 2, I show for each of the six equilibria in stage 2 whether the equilibrium is on the equilibrium path and derive the optimal stage 1 strategies. The six stage 2 equilibria are graphically represented in figure A.8 and characterized in Lemma 4 to 9 in Appendix A.

\section{(1) The unconstrained equilibrium (UCI)}

Assume we are in the UCI equilibrium of stage 2, which is fully characterized in Lemma 4 of Appendix A.

At stage 1, the conventional producer maximizes $\pi_{c}^{*} U C I\left(f_{c}, f_{r}\right)=\frac{1}{9}\left(a-\tau-f_{c}-\right.$ $\left.f_{r}-2 c\right)\left(a-\tau+2 f_{c}-f_{r}-2 c\right)$ and the renewable producer maximizes $\pi_{r}^{*} U C I\left(f_{c}, f_{r}\right)=$ $\frac{1}{9}\left(a+2 \tau-f_{r}-f_{c}+c\right)\left(a+2 \tau+2 f_{r}-f_{c}+c\right)$. The solutions to the two problems are $f_{c}^{U C I}\left(f_{r}\right)=\frac{1}{4}\left(a-\tau-f_{r}-2 c\right)$ and $f_{r}^{U C I}\left(f_{c}\right)=\frac{1}{4}\left(a+2 \tau-f_{c}+c\right)$ respectively, which intersect at $f_{c}^{* U C I}=\frac{1}{5}(a-2 \tau-3 c)$ and $f_{r}^{* U C I}=\frac{1}{5}(a+3 \tau+2 c)$.

\section{Conventional producer}

Given the necessary condition for the UCI equilibrium, $f_{r} \geq-a-\tau$, and the renewable producer's optimal forward market quantity, $f_{r}^{* U C I}=\frac{1}{5}(a+3 \tau+2 c)$, the conventional producer's profit in stage 2 is:

(a) if $-a-\tau+2 k>f_{r}^{*} U C I \geq-a-\tau$

i.e. $k>\frac{1}{5}(3 a+4 \tau+c)$

$\pi_{c}\left(f_{c}, f_{r}^{*} U C I\right)=$

$$
\begin{cases}0 & \text { if } f_{c}<-\frac{2}{5}(a-2 \tau-3 c) \\ \frac{1}{9}\left[\frac{4}{5}(a-2 \tau-3 c)-f_{c}\right]\left[\frac{4}{5}(a-2 \tau-3 c)+2 f_{c}\right] & \text { if }-\frac{2}{5}(a-2 \tau-3 c) \leq f_{c} \leq \frac{1}{5}(7 a+16 \tau+9 c) \\ \frac{1}{4}\left(a-f_{c}-c\right)\left(a+f_{c}-c\right) & \text { otherwise }\end{cases}
$$

This profit function is continuous. It is non-decreasing at $f_{c}=-\frac{2}{5}(a-2 \tau-3 c)$ if and only if $a \geq 2 \tau+3 c$. It is always decreasing at $f_{c}=\frac{1}{5}(7 a+16 \tau+9 c)$. Therefore, if $k>\frac{1}{5}(3 a+4 \tau+c)$ the conventional producer has no incentive to deviate from the UCI equilibrium if and only if $a \geq 2 \tau+3 c$.

(b) if $f_{r}^{* U C I} \geq-a-\tau+2 k$

i.e. $k \leq \frac{1}{5}(3 a+4 \tau+c)$

$\pi_{c}\left(f_{c}, f_{r}^{* U C I}\right)=$

$$
\left\{\begin{array}{l}
0 \\
\frac{1}{4}\left(a-k-f_{c}-c\right)\left(a-k+f_{c}-c\right) \\
\frac{1}{9}\left[\frac{4}{5}(a-2 \tau-3 c)-f_{c}\right]\left[\frac{4}{5}(a-2 \tau-3 c)+2 f_{c}\right] \\
\frac{1}{4}\left(a-f_{c}-c\right)\left(a+f_{c}-c\right)
\end{array}\right.
$$

if $f_{c}<c-a+k$

if $c-a+k \leq f_{c} \leq \frac{1}{5}(7 a+16 \tau+9 c)-3 k$

if $\frac{1}{5}(7 a+16 \tau+9 c)-3 k<f_{c} \leq \frac{1}{5}(7 a+16 \tau+9 c)$

otherwise 
This profit function is continuous. It is always increasing at $f_{c}=c-a+k$ and always decreasing at $f_{c}=\frac{1}{5}(7 a+16 \tau+9 c)$. It is maximized at $f_{c}^{*} U C I=\frac{1}{5}(a-2 \tau-$ $3 c)$ if and only if $k>\max \left\{\frac{2}{5}(a+3 \tau+2 c) ; a-c-\frac{2 \sqrt{2}}{5}(a-2 \tau-3 c)\right\}$. Therefore, if $k \leq \frac{1}{5}(3 a+4 \tau+c)$ the conventional producer has no incentive to deviate from the UCI equilibrium if and only if $k>\max \left\{\frac{2}{5}(a+3 \tau+2 c) ; a-c-\frac{2 \sqrt{2}}{5}(a-2 \tau-3 c)\right\}$.

Because $\frac{1}{5}(3 a+4 \tau+c) \geq \max \left\{\frac{2}{5}(a+3 \tau+2 c) ; a-c-\frac{2 \sqrt{2}}{5}(a-2 \tau-3 c)\right\}$ if and only if $a \geq 2 \tau+3 c$ and because $a \geq 2 \tau+3 c$ implies $a-c-\frac{2 \sqrt{2}}{5}(a-2 \tau-3 c) \geq$ $\frac{2}{5}(a+3 \tau+2 c)$, I conclude that if $k \leq \frac{1}{5}(3 a+4 \tau+c)$, the conventional producer has no incentive to deviate from the UCI equilibrium if and only if $a \geq 2 \tau+3 c$ and $k>a-c-\frac{2 \sqrt{2}}{5}(a-2 \tau-3 c)$.

Bringing (a) and (b) together:

The conventional producer has no incentive to deviate from the UCI equilibrium if $a \geq 2 \tau+3 c$ and $k>a-c-\frac{2 \sqrt{2}}{5}(a-2 \tau-3 c)$.

\section{Renewable producer}

Given the necessary condition for the UCI equilibrium, $f_{c} \geq c-a$, and the conventional producer's optimal forward market quantity, $f_{c}^{*} U C I=\frac{1}{5}(a-2 \tau-3 c)$, the renewable producer's profit in stage 2 is:

(a) if $c-a+k>f_{c}^{*} U C I \geq c-a$

i.e. $k>\frac{2}{5}(3 a-\tau-4 c)$ and $a \geq \frac{1}{3}(\tau+4 c)$

$\pi_{r}\left(f_{c}^{* U C I}, f_{r}\right)=$

$\begin{cases}0 & \text { if } f_{r}<-\frac{2}{5}(a+3 \tau+2 c) \\ \frac{1}{9}\left[\frac{4}{5}(a+3 \tau+2 c)-f_{r}\right]\left[\frac{4}{5}(a+3 \tau+2 c)+2 f_{r}\right] & \text { if }-\frac{2}{5}(a+3 \tau+2 c) \leq f_{r} \leq \frac{1}{5}(7 a-9 \tau-16 c) \\ \frac{1}{4}\left(a+\tau-f_{r}\right)\left(a+\tau+f_{r}\right) & \text { if } \frac{1}{5}(7 a-9 \tau-16 c)<f_{r}<-a-\tau+2 k \\ (a+\tau-k) k & \text { otherwise }\end{cases}$

This profit function is continuous. It is constant in $f_{r}$ for $f_{r} \geq-a-\tau+2 k$. It is always increasing at $f_{r}=-\frac{2}{5}(a+3 \tau+2 c)$. It is non-increasing at $f_{r}=$ $\frac{1}{5}(7 a-9 \tau-16 c)$ if and only if $a \geq 2 \tau+3 c$. If $a \geq 2 \tau+3 c$, it is always decreasing left of $f_{r}=-a-\tau+2 k$. (Note that $2 \tau+3 c>\frac{1}{3}(\tau+4 c)$.) Therefore, if $k>\frac{2}{5}(3 a-\tau-4 c)$ the renewable producer has no incentive to deviate from the UCI equilibrium if and only if $a \geq 2 \tau+3 c$.

(b) if $f_{c}^{*} U C I \geq c-a+k$

i.e. $k \leq \frac{2}{5}(3 a-\tau-4 c)$

$\pi_{r}\left(f_{c}^{*} U C I, f_{r}\right)=$

$$
\begin{cases}0 & \text { if } f_{r}<-\frac{2}{5}(a+3 \tau+2 c) \\ \frac{1}{9}\left[\frac{4}{5}(a+3 \tau+2 c)-f_{r}\right]\left[\frac{4}{5}(a+3 \tau+2 c)+2 f_{r}\right] & \text { if }-\frac{2}{5}(a+3 \tau+2 c) \leq f_{r}<-\frac{2}{5}(a+3 \tau+2 c)+\frac{3}{2} k \\ \left.\frac{1}{2}\left[\frac{4}{5}(a+3 \tau+2 c)-k\right)\right] k & \text { otherwise }\end{cases}
$$


This profit function is continuous. It is constant in $f_{r}$ for $f_{r} \geq-\frac{2}{5}(a+3 \tau+2 c)+\frac{3}{2} k$. It is always increasing at $f_{r}=-\frac{2}{5}(a+3 \tau+2 c)$. It is decreasing at $f_{r}=-\frac{2}{5}(a+$ $3 \tau+2 c)+\frac{3}{2} k$ if and only if $k>\frac{2}{5}(a+3 \tau+2 c)$. Therefore, if $k \leq \frac{2}{5}(3 a-\tau-4 c)$ the renewable producer has no incentive to deviate from the UCI equilibrium if and only if $k>\frac{2}{5}(a+3 \tau+2 c)$.

Because $\frac{2}{5}(3 a-\tau-4 c) \geq \frac{2}{5}(a+3 \tau+2 c)$ if and only if $a \geq 2 \tau+3 c$, I conclude that if $k \leq \frac{2}{5}(3 a-\tau-4 c)$ the renewable producer has no incentive to deviate from the UCI equilibrium if and only if $a \geq 2 \tau+3 c$ and $k>\frac{2}{5}(a+3 \tau+2 c)$.

Bringing (a) and (b) together:

The renewable producer has no incentive to deviate from the UCI equilibrium if $a \geq 2 \tau+3 c$ and $k>\frac{2}{5}(a+3 \tau+2 c)$.

\section{Both producers}

Finally, because $a \geq 2 \tau+3 c$ implies $a-c-\frac{2 \sqrt{2}}{5}(a-2 \tau-3 c) \geq \frac{2}{5}(a+3 \tau+2 c)$, I conclude that the unconstrained interior equilibrium is subgame perfect if and only if $k>a-c-\frac{2 \sqrt{2}}{5}(a-2 \tau-3 c)$ and $a \geq 2 \tau+3 c$.

\section{(2) The constrained equilibrium (CI)}

Assume we are in the CI equilibrium of stage 2, which is fully characterized in Lemma 5 of Appendix A.

At stage 1, the conventional producer maximizes $\pi_{c}^{* C I}\left(f_{c}, f_{r}\right)=\frac{1}{4}(a-k-$ $\left.f_{c}-c\right)\left(a-k+f_{c}-c\right)$ and the renewable producer maximizes $\pi_{r}^{*}{ }^{C I}\left(f_{c}, f_{r}\right)=$ $\frac{1}{2}\left(a+2 \tau-k-f_{c}+c\right) k$. The solutions to the two problems are $f_{c}^{*} C I=0$ and $f_{r}^{* C I}=$ any.

\section{Conventional producer}

Given the necessary condition for the CI equilibrium, $f_{r} \geq-a-\tau+2 k$, and given the renewable producer's optimal forward market quantity, $f_{r}^{*} C I=$ any, the conventional producer's profit in stage 2 is:

$$
\begin{aligned}
& \pi_{c}\left(f_{c}, f_{r}^{*} C I\right)= \\
& \begin{cases}0 & \text { if } f_{c}<c-a+k \\
\frac{1}{4}\left(a-k-f_{c}-c\right)\left(a-k+f_{c}-c\right) & \text { if } c-a+k \leq f_{c} \leq a+2 \tau+c+2 f_{r}-3 k \\
\frac{1}{9}\left(a-\tau-f_{c}-f_{r}-2 c\right)\left(a-\tau+2 f_{c}-f_{r}-2 c\right) & \text { if } a+2 \tau+c+2 f_{r}-3 k<f_{c} \leq a+2 \tau+c+2 f_{r} \\
\frac{1}{4}\left(a-f_{c}-c\right)\left(a+f_{c}-c\right) & \text { otherwise }\end{cases}
\end{aligned}
$$

This profit function is continuous. It is always increasing at $f_{c}=c-a+k$ and always decreasing at $f_{c}=a+2 \tau+c+2 f_{r}$. It is maximized at $f_{c}^{*} C I=0$ if and only if $f_{r} \geq a-\tau-2 c-\sqrt{2}(a-c-k)$, which is always satisfied at $f_{r}^{*} C I=a n y$. The conventional producer never has an incentive to deviate from the CI equilibrium.

\section{Renewable producer}


Given the necessary condition for the CI equilibrium, $f_{c} \geq c-a+k$, and given the conventional producer's optimal forward market quantity, $f_{c}^{*} C I=0$, the renewable producer's profit in stage 2 is:

$$
\begin{aligned}
& \pi_{r}\left(f_{c}^{*} C I, f_{r}\right)= \\
& \quad \begin{cases}0 & \text { if } f_{r}<-\frac{1}{2}(a+2 \tau+c) \\
\frac{1}{9}\left(a+2 \tau-f_{r}+c\right)\left(a+2 \tau+2 f_{r}+c\right) & \text { if }-\frac{1}{2}(a+2 \tau+c) \leq f_{r}<-\frac{1}{2}(a+2 \tau+c)+\frac{3}{2} k \\
\frac{1}{2}(a+2 \tau-k+c) k & \text { otherwise }\end{cases}
\end{aligned}
$$

This profit function is continuous. It is constant in $f_{r}$ for $f_{r} \geq-\frac{1}{2}(a+2 \tau+c)+\frac{3}{2} k$. It is always increasing at $f_{r}=-\frac{1}{2}(a+2 \tau+c)$. It is non-decreasing at $f_{r}=$ $-\frac{1}{2}(a+2 \tau+c)+\frac{3}{2} k$ if and only if $k \leq \frac{1}{2}(a+2 \tau+c)$. Therefore, the renewable producer has no incentive to deviate from the CI equilibrium if and only if $k \leq \frac{1}{2}(a+2 \tau+c)$.

$k=\frac{1}{2}(a+2 \tau+c)$ lies outside the parameter space considered by this model if $a<$ $2 \tau+3 c$ (by assumption $a-k>c$ ). Therefore, if $a<2 \tau+3 c$ the renewable producer never has an incentive to deviate from the CI equilibrium in the parameter space considered by this model.

\section{Both producers}

Finally, I conclude that the constrained interior equilibrium is subgame perfect if $a<2 \tau+3 c$ or if $a \geq 2 \tau+3 c$ and $k \leq \frac{1}{2}(a+2 \tau+c)$.

\section{(3) The unconstrained renewable monopoly (UCRM)}

Assume we are in the UCRM equilibrium of stage 2, which is fully characterized in Lemma 6 of Appendix A.

At stage 1, the conventional producer maximizes $\pi_{c}^{* U C R M}\left(f_{c}, f_{r}\right)=0$ and the renewable producer maximizes $\pi_{r}^{*} U C R M\left(f_{c}, f_{r}\right)=\frac{1}{4}\left(a+\tau-f_{r}\right)\left(a+\tau+f_{r}\right)$. The solutions to the two problems are $f_{c}^{* U C R M}=$ any and $f_{r}^{* U C R M}=0$.

\section{Conventional producer}

Given the necessary conditions for the UCRM equilibrium, $-a-\tau+2 k>$ $f_{r} \geq-a-\tau$, and given the renewable producer's optimal forward market quantity, $f_{r}^{* U C R M}=0$, the conventional producer's profit in stage 2 is:

$\pi_{c}\left(f_{c}, f_{r}^{*} U C R M\right)=$

$$
\begin{cases}0 & \text { if } f_{c}<-\frac{1}{2}(a-\tau-2 c) \\ \frac{1}{9}\left(a-\tau-f_{c}-2 c\right)\left(a-\tau+2 f_{c}-2 c\right) & \text { if }-\frac{1}{2}(a-\tau-2 c) \leq f_{c} \leq a+2 \tau+c \\ \frac{1}{4}\left(a-f_{c}-c\right)\left(a+f_{c}-c\right) & \text { otherwise }\end{cases}
$$

This profit function is continuous. It is decreasing at $f_{c}=-\frac{1}{2}(a-\tau-2 c)$ if and only if $a<\tau+2 c$. It is always decreasing at $f_{c}=a+2 \tau+c$. Therefore, the conventional producer has no incentive to deviate from the UCRM if and only if $a<\tau+2 c$. 


\section{Renewable producer}

Given the necessary conditions for the UCRM equilibrium, $f_{c}<c-a+k$, and given the conventional producer's optimal forward market quantity, $f_{c}^{*} U C R M=$ any, the renewable producer's profit in stage 2 is:

(a) if $f_{c}<c-a$

$\pi_{r}\left(f_{c}^{*} U C R M, f_{r}\right)=$

$$
\begin{cases}0 & \text { if } f_{r}<-a-\tau \\ \frac{1}{4}\left(a+\tau-f_{r}\right)\left(a+\tau+f_{r}\right) & \text { if }-a-\tau \leq f_{r}<-a-\tau+2 k \\ (a+\tau-k) k & \text { otherwise }\end{cases}
$$

This profit function is continuous. It is constant in $f_{r}$ for $f_{r} \geq-a-\tau+2 k$. It is always increasing at $f_{r}=-a-\tau$. It is decreasing at $f_{r}=-a-\tau+2 k$ if and only if $k>\frac{1}{2}(a+\tau)$. Therefore, if $f_{c}<c-a$ the renewable producer has no incentive to deviate from the UCRM if and only if $k>\frac{1}{2}(a+\tau)$.

(b) if $c-a \leq f_{c}<c-a+k$

$$
\begin{aligned}
& \pi_{r}\left(f_{c}^{* U C R M}, f_{r}\right)= \\
& \begin{cases}0 & \text { if } f_{r}<-\frac{1}{2}\left(a+2 \tau+c-f_{c}\right) \\
\frac{1}{9}\left(a+2 \tau-f_{r}-f_{c}+c\right)\left(a+2 \tau+2 f_{r}-f_{c}+c\right) & \text { if }-\frac{1}{2}\left(a+2 \tau+c-f_{c}\right) \leq f_{r} \leq a-\tau-2 c+2 f_{c} \\
\frac{1}{4}\left(a+\tau-f_{r}\right)\left(a+\tau+f_{r}\right) & \text { if } a-\tau-2 c+2 f_{c}<f_{r}<-a-\tau+2 k \\
(a+\tau-k) k & \text { otherwise }\end{cases}
\end{aligned}
$$

This profit function is continuous. It is constant in $f_{r}$ for $f_{r} \geq-a-\tau+2 k$. It is always increasing at $-\frac{1}{2}\left(a+2 \tau+c-f_{c}\right)$. It is increasing at $f_{r}=a-\tau-2 c+2 f_{c}$ if and only if $a<\tau+2 c-2 f_{c}$. It is decreasing in $f_{r}=-a-\tau+2 k$ if and only if $k>\frac{1}{2}(a+\tau)$. Therefore, if $c-a \leq f_{c}<c-a+k$ the renewable producer has no incentive to deviate from the UCRM if and only if $a<\tau+2 c-2 f_{c}$ and $k>\frac{1}{2}(a+\tau)$.

\section{Both producers}

Finally, if the conventional producer has no incentive to deviate from the UCRM, the renewable producer will always have an incentive to deviate, because $a<\tau+2 c$ implies that $k=\frac{1}{2}(a+\tau)$ lies outside the parameter range considered by this model (by assumption $a-k>c$ ).

I conclude that the unconstrained renewable monopoly is never on the equilibrium path.

(4) The constrained renewable monopoly (CRM)

Assume we are in the CRM equilibrium of stage 2, which is fully characterized in Lemma 7 of Appendix A. 
At stage 1, the conventional producer maximizes $\pi_{c}^{*} C R M\left(f_{c}, f_{r}\right)=0$ and the renewable producer maximizes $\pi_{r}^{*} C R M\left(f_{c}, f_{r}\right)=(a+\tau-k) k$. The solutions to the two problems are $f_{c}^{*} C R M=$ any and $f_{r}^{* C R M}=$ any.

\section{Conventional producer}

Given the necessary condition for the CRM equilibrium, $f_{r} \geq-a-\tau+2 k$, and given the renewable producer's optimal forward market quantity, $f_{r}^{*} C R M=$ any, the conventional producer's profit in stage 2 is:

$$
\begin{aligned}
& \pi_{c}\left(f_{c}, f_{r}^{*} C R M\right)= \\
& \begin{cases}0 & \text { if } f_{c}<c-a+k \\
\frac{1}{4}\left(a-k-f_{c}-c\right)\left(a-k+f_{c}-c\right) & \text { if } c-a+k \leq f_{c} \\
\frac{1}{9}\left(a-\tau-f_{c}-f_{r}-2 c\right)\left(a-\tau+2 f_{c}-f_{r}-2 c\right) & \text { if } a+2 \tau+c+2 f_{r} \\
\frac{1}{4}\left(a-f_{c}-c\right)\left(a+f_{c}-c\right) & \text { otherwise }\end{cases}
\end{aligned}
$$$$
\text { if } c-a+k \leq f_{c} \leq a+2 \tau+c+2 f_{r}-3 k
$$$$
\text { if } a+2 \tau+c+2 f_{r}-3 k<f_{c} \leq a+2 \tau+c+2 f_{r}
$$

otherwise

This profit function is continuous. It is always increasing at $f_{c}=c-a+k$. Therefore, the conventional producer always has an incentive to deviate from the CRM.

I conclude that the constrained renewable monopoly is never on the equilibrium path.

\section{(5) The conventional monopoly (CM)}

Assume we are in the CM equilibrium of stage 2, which is fully characterized in Lemma 8 of Appendix A.

At stage 1 , the conventional producer maximizes $\pi_{c}^{*} C M\left(f_{c}, f_{r}\right)=\frac{1}{4}\left(a-f_{c}-\right.$ $c)\left(a+f_{c}-c\right)$ and the renewable producer maximizes $\pi_{r}^{*} C M\left(f_{c}, f_{r}\right)=0$. The solutions to the two problems are $f_{c}^{*} C M=0$ and $f_{r}^{*} C M=$ any.

\section{Renewable producer}

Given the necessary condition for the $\mathrm{CM}$ equilibrium, $f_{c} \geq c-a$, and given the conventional producer's optimal forward market quantity, $f_{c}^{*} C M=0$, the renewable producer's profit in stage 2 is:

(a) if $f_{c}^{*} C M>c-a+k$

i.e. $a-k>c$

$$
\pi_{r}\left(f_{c}^{*} C M, f_{r}\right)=
$$

$$
\begin{cases}0 & \text { if } f_{r}<-\frac{1}{2}(a+2 \tau+c) \\ \frac{1}{9}\left(a+2 \tau-f_{r}+c\right)\left(a+2 \tau+2 f_{r}+c\right) & \text { if }-\frac{1}{2}(a+2 \tau+c) \leq f_{r}<-\frac{1}{2}(a+2 \tau+c)+\frac{3}{2} k \\ \frac{1}{2}(a+2 \tau-k+c) k & \text { otherwise }\end{cases}
$$

This profit function is continuous. It is always increasing at $f_{r}=-\frac{1}{2}(a+2 \tau+c)$. Therefore, if $f_{c}>c-a+k$, the renewable producer always has an incentive to 
deviate from the CM.

(b) if $c-a+k>f_{c}^{*} C M \geq c-a$

i.e. $k>a-c$ which lies outside the parameter range considered by this model (by assumption $a-k>c$ ).

I conclude that the conventional monopoly is never on the equilibrium path.

(6) The "no one produces" equilibrium (NO)

Assume we are in the NO equilibrium of stage 2, which is fully characterized in Lemma 9 of Appendix A.

At stage 1 , the conventional producer maximizes $\pi_{c}^{*}{ }^{N O}\left(f_{c}, f_{r}\right)=0$ and the renewable producer maximizes $\pi_{r}^{*}{ }^{N O}\left(f_{c}, f_{r}\right)=0$. The solutions to the two problems are $f_{c}^{*} N O=$ any and $f_{r}^{*} N O=$ any.

\section{Conventional producer}

Given the necessary condition for the NO equilibrium, $f_{r}<-a-\tau$, the conventional producer's profit in stage 2 is:

$$
\pi_{c}\left(f_{c}, f_{r}^{* N O}\right)= \begin{cases}0 & \text { if } f_{c}<c-a \\ \frac{1}{4}\left(a-f_{c}-c\right)\left(a+f_{c}-c\right) & \text { otherwise }\end{cases}
$$

This profit function is continuous. It is always increasing at $f_{c}=c-a$. Therefore, the conventional producer always has an incentive to deviate from the NO equilibrium.

I conclude that the "no one produces" equilibrium is never on the equilibrium path.

\section{Appendix D. Equilibria in the counterfactual model}

Solving the fixed premium model of Section 4 but forcing $f_{c}=f_{r}=0$ results in two Nash equilibria that are given in the following theorem.

\section{Theorem 3. Equilibrium (Counterfactual):}

There are two Nash equilibria in the counterfactual model.

- If $k>\frac{1}{3}(a+2 \tau+c)$ and $\tau \leq a-2 c$, there is a unique unconstrained Nash equilibrium (UNE) with optimal equilibrium quantities $q_{c}^{*} U N E=\frac{1}{3}(a-\tau-2 c)$ and $q_{r}^{*} U N E=\frac{1}{3}(a+2 \tau+c)$.

The unique Nash equilibrium price is $p^{* U N E}=\frac{1}{3}(a-\tau+c)$.

- Otherwise, there is a unique constrained Nash equilibrium with optimal equilibrium quantities $q_{c}^{*} C N E=\frac{1}{2}(a-k-c)$ and $q_{r}^{*} C N E=k$.

The unique Nash equilibrium price is $p^{*} C N E=\frac{1}{2}(a-k+c)$. 